ISSN: 2146-3042

DOI: $10.25095 /$ mufad.801058

\title{
Bir Üretim İşletmesinde Tamsayılı Programlama ile Ürün Karması Kararı: Faaliyete Dayalı Maliyet Sistemi ve Kısıtlar Teorisi Uygulaması*
}

\author{
Elif N. DEMİRCIOĞLLU** \\ Mert DEMIRCIOĞLUU*** \\ Nihat KÜÇÜKSAVAŞ****
}

\begin{abstract}
ÖZET
Ürün karması kararları işletme kârlılı̆̆ının arttırılmasında oldukça büyük önem taşımaktadır ancak geleneksel yöntemler en uygun ürün karması belirlemede yetersiz kalabilmektedir. Bu amaçla yeni geliştirilen teknikler daha kârlı sonuçlar sağlayabilmektedir. Bu çalışmada çağdaş yöntemlerden Faaliyete Dayalı Maliyet Sistemi (FDM) ve Kısıtlar Teorisinin (KT) birlikte kullanılmasıyla belirlenen ürün karması ile daha yüksek kârlar elde edilebileceği belirlenmeye çalışlmıştır. Bu doğrultuda bu çalışmanın amacı işletmelerin kârlılıklarını arttırabilmek için ürün karması kararlarının önemini vurgulayarak, doğru ürün karması kararları alabilmede geleneksel yöntemler yerine, kisitlar teorisi ve faaliyete dayalı maliyet sisteminin birlikte kullanılmasinın önemini ortaya koymaktır. Bu çerçevede bir üretim işletmesinde tanımlayıcı ve keşifsel olay çalışmaları olmak üzere iki tür olay çalışması yapılmıştır. Tanımlayıcı olay çalışması ile işletmenin mevcut üretim ve maliyet sistemi ortaya konulmuş, keşifsel olay çalışması ile de kisttlar teorisi ve faaliyete dayalı maliyet sisteminin birlikte kullanılmastyla belirlenecek ürün karmasının işletme kârlılığını ne ölçüde etkilediği ortaya konulmuştur. Tamsayılı programlamadan yararlanılarak yapılan analizlerde ve çözümlemelerde MATLAB ve WINQSB programları kullanılmıştır.

Anahtar Kelimeler: Ürün Karması, Tamsayılı Programlama, Geleneksel Tam Maliyet Sistemi, Faaliyete Dayalı Maliyet Sistemi, Klsitlar Teorisi.

JEL Siniflandirmasi: $M 40$, M41
\end{abstract}

Product Mix Decision by Using Integer Programming in a Manufacturing Company: Activity Based Costing and Theory of Constraints Application

\section{ABSTRACT}

Product mix decisions are very important to increase the profitability of companies but traditional methods are inadequate in these decisions. Contemporary techniques which have been developed for this purpose can create more profitable solutions. In this study, activity based costing and theory of constraints were integrated in product mix decisions to determine companies whether to acquire higher profits. Accordingly, the aim of this study is to emphasize the importance of the optimal product mix decisions to increase companies' profit and expose the importance of integrating activity based costing and theory of constraints in making rational and profitable product mix decisions. For this purpose, descriptive and exploratory case studies were applied in a manufacturing company. First, existing production and cost systems of the selected company were defined by a descriptive case study; and then by applying an exploratory case study, it was showed that how profitability of the company was affected by the product mix which is determined through the integration of theory of constraints and activity based costing. By means of integer programming, MATLAB and WINQSB are used to solve the problems.

Keywords: Product Mix, Integer Programming, Traditional Absorption Costing, Activity Based Costing, Theory Of Constraints.

Jel Classification: M40, M41

\footnotetext{
* Makale Geliş Tarihi : 25.12.2019, Makale Kabul Tarihi: 27.2.2020, Makale Türü: Örnek Olay Çalışması Çalışma Elif N. Ünal (Demircioğlu)’nun 2006 yılında Çukurova Üniversitesi SBE’ne sunulan doktora tezinden hazırlanmıştır.

** Çukurova Üniversitesi, İktisadi ve İdari Bilimler Fakültesi, elunal@cu.edu.tr, ORCID: 0000-0001-9711-2081.

*** Dr. Öğr. Üyesi, Çukurova Üniversitesi, İktisadi ve İdari Bilimler Fakültesi, mdemircioglu@cu.edu.tr, ORCID: 0000-0002-2287-2067.

**** Prof. Dr., Beykent Üniversitesi, İktisadi ve İdari Bilimler Fakültesi, nihatkucuksavas@beykent.edu.tr, ORCID: 0000-0002-6243-7465.
} 


\section{GÍRIŞ}

Ürün karması kararları işletmelerin kârlılıklarını arttırmada oldukça önemli olmaktadır zira kapasite kısıtı söz konusu iken mevcut kapasiteleri ile taleplerin tamamını karşılamak mümkün olamayacağından, işletmelerin aldıkları ürün karması kararları, kârlılıklarının belirleyicisi olmaktadır. Dolayısıyla işletmeler, kârlarını en yüksek kılacak ürün karması belirlemelidirler. Geleneksel yöntemlerden tam maliyet sisteminde ürünlerle ilgili alınacak kararlarda esas olarak birim başına kârlar dikkate alınmakta, değişken maliyet sisteminde ise birim katkılar esas alınmaktadır (Küçüksavaş, 1992:100; Blackstone, 2001:1060). Ancak geleneksel yöntemler bu konuda yetersiz kalabildiğinden yeni yöntemlere ihtiyaç doğmaktadır (Alsmadi, Almani ve Khan, 2014:907).

Bu yeni yöntemlerden Kısıtlar Teorisi (KT) ile ürün karması belirlenirken hammadde maliyetleri tek değişken maliyet olarak dikkate alınmakta, işçilik ve GÜM işletmenin etkilemediği kaynaklar olarak sabit maliyet varsayılmakta ve toplam kapasite dikkate alınmaktadır (Kee, 1995:50; Kee ve Schmidt, 2000:3; Fu, 2000:70, Tsai, Chena, Leua ve Changa, 2013:179). Bu doğrultuda, süreç katkısı (throughput), satış gelirlerinden hammadde maliyetlerinin çıkarılması sonucu elde edilmekte ve dolayısıyla ürün karması ile ilgili alınacak kararlarda, kısıtlı kaynakta kapasite birimi başına süreç katkısı dikkate alınmaktadır (Goldratt ve Fox, 1986:28; Louderback ve Patterson, 1996:190; Izmailov, 2014:925). KT’nin kısa vadeli bakış açısına sahip olması uzun vadeli stratejik karar almadaki faydasını azaltmaktadır (Kee, 1995:50-51; MacArthur, 1993:52-53). Faaliyete Dayalı Maliyet Sistemi (FDM) ile ise faaliyetler, ürünler ve maliyetler arasındaki neden-sonuç ilişkisi ortaya konulduğundan uzun vadeli kararlar için faydalı bilgiler sağlanmaktadır (Perkins, Stewart ve Stoval, 2002:2). Zira FDM ile kaynak maliyetleri maliyet objelerine iki aşamalı dağıtım süreci ile dağıtılmakta olup, birinci aşamada kaynak maliyetleri, kaynak taşıyıcıları ile faaliyet maliyeti havuzlarına, ikinci aşamada ise faaliyet taşıyıcıları ile faaliyet maliyeti havuzlarından maliyet objelerine kullanımlarına göre dağıtılmaktadır (Tsai ve diğerleri, 2013:179; Huang, Chen, Chiu ve Chen, 2014:534). Bu sayede FDM ile genel üretim giderlerinin ürünlere geleneksel yöntemlere göre daha doğru dağıtımı sağlanmakta ve dolayısıyla daha doğru kararlar alınabilmektedir (Tsai ve diğerleri, 2013:179). Ayrıca FDM faaliyet haritası (activity mapping) ile işletmede kaynaklar arasındaki ilişkiler tespit edilmekte, bu da yönetime kısıtların nerede olduğu konusunda yardımcı olmaktadır (Salafatinos, 1995:59). Kısaca FDM ile faaliyetler detaylı olarak analiz edildiğinden, katma değer yaratan ve katma değer yaratmayan faaliyetler tespit edilebilmekte, bu sayede darboğazlar tespit edilebileceği için KT uygulamasını kolaylaştırmaktadır (Tsai ve diğerleri, 2013:179; Tanış, 1999:153, Massood, 1995:39). Ancak FDM bu kisitların belirlenip ortadan kaldırılmas1 ve bu kisitları üretimle ilgili kararlarda dikkate alma konusunda yeterli olamamaktadır (Kee, 1995:50; Kee ve Schmidt, 2000:3; Tsai ve diğerleri, 2013:178, Massood, 1995:39). Bu problem, KT kullanılarak giderilebilmektedir, zira KT'de bir sistemin başarısını (kârlılığını) kısıtlar belirlemekte ve bu kısitların belirlenip ortadan kaldırılması ile işletme kârlılı̆g arttırılabilmektedir (Alsmadi ve diğerleri, 2014; Huang ve diğerleri, 2014:534). Özetle, KT ile işletmenin kısa vadeli kârlılığının artması sağlanmakta olup, bu problem FDM ile giderilebilmektedir, zira FDM'de amaç uzun vadeli kârlılığı arttırmaktır (Alsmadi ve diğerleri, 2014:910; Kee, 1995; Huang ve diğerleri, 2014). FDM'de ürün karması kararı alınırken kullanılan kaynak kapasitesi dikkate alınmakta, KT'de ise toplam kapasite dikkate alınmaktadır (Kee, 1995:50-51). Yani FDM'e göre hammadde maliyetleri dişındaki maliyetler (işçilik ve GÜM) kontrol edilebilir maliyetler olarak dikkate alınırken, KT’e göre 
bu maliyetlerin hepsi kontrol edilemeyen sabit maliyetler olarak dikkate alınmaktadır (Kee, 1995:50-51). Her iki yöntemin en uygun ürün karması belirlemek üzere birlikte kullanılmasında ise bu maliyetlerin bir kısmının kontrol edilebilir, bir kısmının ise kontrol edilemeyen maliyetler olarak dikkate alınması sözkonusudur ki bu şekilde belirlenen ürün karması ile daha yüksek kârlar elde edilebilmektedir (Kee ve Schmidt, 2000:3).

Özetle FDM ve KT birbirine zit alternatifler olarak algilanmaktadır ancak bu iki yöntem aslında birbirlerine zıt değil birbirlerinin tamamlayıcısı olabilmektedir (Alsmadi ve diğerleri, 2014:912; MacArthur, 1993:52-53; Huang ve diğerleri, 2014:535). Her iki yöntemin birlikte kullanılması ile işletmelerin daha doğru ürün karması kararları alabilmeleri ve dolayısıyla kârlılıklarını arttırması sağlanabilmektedir (Alsmadi ve diğerleri, 2014:917-918; Huang ve diğerleri, 2014:533). Zira her iki yöntem de ayrı ayrı avantaj ve dezavantajlara sahip olup, her ikisinin biribirinin eksik yönlerini tamamlayarak birlikte kullanılması ile işletme kârının daha yüksek olmasını sağlayacak ürün karması belirlenebilmektedir (Alsmadi ve diğerleri, 2014:917-918; Huang ve diğerleri, 2014:533). Bunun yanında son yıllarda zamana dayalı faaliyete dayalı maliyet sisteminin optimal ürün karması kararlarında kullanımına ilişkin çalışmalar da yapılmıştır. Bu doğrultuda Zheng-Yun Zhuang ve Shu-Chin Chang (2017:959-974) yaptıkları çalışmada, kısıtlar teorisi, faaliyete dayalı maliyet sistemi ve zamana dayalı faaliyete dayalı maliyet sistemlerini açıklamış ve bu yöntemlere göre karma tamsayılı programlama ile modeller kurarak çözümlemeler yapmış ve en yüksek kârlılığın zamana dayalı faaliyete dayalı maliyet sistemi ile elde edilebileceğini göstermiştir. WenHsien Tsai 1, Jui-Chu Chang, Chu-Lun Hsieh, Tsen-Shu Tsaur ve Chung-Wei Wang (2016:122) yaptıkları çalışmada aynı şekilde kısıtlar teorisi, faaliyete dayalı maliyet sistemi ve zamana dayalı faaliyete dayalı maliyet sistemini optimal çevreye duyarlı ürün karması belirlemede karşılaştırmış, karma tamsayılı programlama ile model geliştirerek çözümlemiş ve en yüksek kârlılığın zamana dayalı faaliyete dayalı maliyet sistemi ile elde edilebileceğini tespit etmişlerdir.

\section{OLAY ÇALIŞMASI YÖNTEMİ İLE UYGULAMA}

Araştırmada izlenen yöntem, olay çalışması (case study) yöntemidir. Olay çalışması yöntemi, belirli bir olay veya durumun (kişi, işletme vs.) derinlemesine incelenmesi olarak tanımlanmakta olup, "nasıl" veya "niçin" sorularının sorulduğu, araştırmacının olaylar üzerinde kontrolünün olmadığı ve güncel olayların incelendiği durumda uygun olan bir araştırma yöntemidir (Macpherson, Unitoker ve Ainsword, 2000:52; Yin, 1994:6). Araştırma yöntemi olarak olay çalışmasının seçilmesinin nedeni, bu şekilde elde edilecek verilerin diğer yöntemlere oranla daha derin, detaylı ve güvenilir veriler sağlamasıdır. Araştırmanın amacı FDM ve KT'nin birlikte kullanılması yoluyla en uygun ürün karmasının belirlenmesi ve bunun işletme kârlılığına etkisini ortaya koymaktır. Bu kapsamda ürün karması belirlemede üretim süreci dikkatli bir şekilde incelenmeli ve süreçteki darboğazlar tespit edilmelidir. Ayrıca ürün karması belirlemede ürünlerle ilgili maliyet bilgilerini doğru bir şekilde tespit etmek gerekmektedir. Bu yüzden araştırma için en uygun yöntem olay çalışması yöntemi olmaktadır. Araştırmada elde edilen verilerin analiz edilmesinde tamsayılı programlamadan yararlanılmıştır. Tamsayılı programlama, karar değişkenlerinin tümünün ya da bir kısmının tamsayı değerler almak zorunda olduğu, doğrusal programlamanın bir uzantısıdır (Ulucan, 2004:211). Tamsayılı programlama, saf tamsayılı programlama, ikili (0-1) tamsayılı programlama ve karma tamsayılı programlama olarak üçe ayrılmaktadır (Hillier ve Lieberman, 1995:494; Render, Stair, Hanna ve Hale, 2018:376). Bu araştırmada saf tamsayılı 
programlamadan yararlanılmış olup, saf tamsayılı programlamada tüm değişkenlerin tamsayı değer alması gerekmektedir (Hillier ve Lieberman, 1995:494; Render, Stair, Hanna ve Hale, 2018:376). Analiz için tamsayılı programlanmadan faydalanmanın nedeni araştırmanın konusunun ve amacının bu programlamayı gerektirmesidir. Tamsayılı programlama doğrusal programlamanın bir uzantısı olduğundan öncelikle neden doğrusal programlamadan faydalanılacağı sorusunu yanıtlamak gerekir ki bunun nedeni değişkenlerin doğrusal (lineer) olmasıdır. İncelenen işletmenin üretim konusu gıda ambalaj ürünleri olup, bu ürünler için (bardak, tabak ve bardak kapağı) ürün karması belirlenmiş, bunun için bütün değişkenler tamsayılı olacağı için saf tamsayılı programlamadan yararlanılmıştır. Modellerin çözümünde neden bilgisayar programlarından yararlanılacağ 1 sorusunun cevabı ise, karar değişkenlerinin ve kısıt sayısının çok fazla olmasıdır. Çözümlemede çözüm algoritması en uygun olan doğrusal programlama yazılımlarından MATLAB ve WINQSB programları kullanılmıştır.

$\mathrm{Bu}$ çalışmada işletmelerin kârlılıklarını arttırabilmelerinde ürün karması kararlarının önemini göstermek üzere, doğru ürün karması kararları alabilmede geleneksel yöntemler yerine, KT ile FDM'nin birlikte kullanımının işletmenin faaliyet sonucuna etkisini ortaya koymak amaçlanmıştır. Bu kapsamda Adana ilinde faaliyet gösteren bir üretim işletmesinde gerçekleştirilen örnek olay (vaka) çalışması ile şu araştırma sorularına cevap aranmıştır;

1. İşletmenin üretim sürecinde kısıtın varolup olmadığ

2. İşletmenin ürün karması kararlarını geleneksel yöntemlere göre belirleyip belirlemedikleri,

3. FDM, KT ve her iki yöntemin birlikte kullanılması ile belirlenen ürün karmasının geleneksel yöntemlere göre belirlenen ürün karmasından daha kârlı sonuçlar yaratıp yaratmadiğı.

Araştırma sorularını cevaplandırmak üzere, bir holding bünyesinde Adana'da faaliyet gösteren, üretim konusu gıda ambalaj ürünleri olan bir işletmede tanımlayıcı (descriptive) ve keşifsel (exploratory) olay çalışması olmak üzere iki tür olay çalışması yapılmıştır. Tanımlayıcı olay çalışması ile işletmenin mevcut ürün karması karar alma yöntemleri incelenmiş ve mevcut kârlılık sonuçları ortaya konulmuştur. Keşifsel olay çalışması ile de, öncelikle FDM ve KT ile ayrı ayrı ürün karmaları belirlenmiş, ardından her iki yöntem birlikte kullanılarak ürün karması belirlenmiştir. Sonuç olarak herbirinin faaliyet sonucuna etkisi ortaya konularak mevcut yöntem sonuçları ile karşılaştırılmıştır.

\section{1. İşletmenin Üretim ve Maliyet Sistemi}

İşletmenin ürünleri; çatı ve cephe kaplamaları, yalıtım ürünleri, strofor (EPS) ambalaj ürünleri, dekoratif ürünler, güvenlik bariyeri, gıda ambalaj ürünlerinden oluşmaktadır. Bu çalışmada gıda ambalaj ürünleri üreten fabrikada inceleme yapılmış olup, bu ürün grubunda; EPS bardaklar, EPS kâseler, EPS kaplar, plastik bardaklar, özel bardaklar, delikli pet kaplar, sızdırmaz pet kaplar, şarküteri kapları, plastik tabaklar, kapaklar ve viyoller, kutular, kartonpiyer, asma tavan ürünleri yer almaktadır. Bu ürünler içerisinde araştırma konusu olarak plastik bardaklar, plastik tabaklar ve kapaklar alınmıştır. Zira diğer ürünler ayrı makinelerde üretildiği ve kısıt yaratmadığ 1 için ürün karması seçiminde dikkate alınmamıştır. Araştırmada incelenen ürünler aşağıdaki gibi nitelendirilmiştir; 
Tablo 1. İşletmenin Ürünleri

\begin{tabular}{|l|l|l|l|}
\hline ÜRÜNLER \\
\hline GN PS f 73,5 Bardak Kapağ1 & $(\mathrm{X} 11)$, & GN PS f 205 Piknik Tabağ1 & $(\mathrm{X} 61)$, \\
\hline GN PS f 80 Bardak Kapağ1 & $(\mathrm{X} 21)$, & TFT PS 80 ml. Bardak & $(\mathrm{X} 71)$, \\
\hline GN PS f 80 Bardak Kapağı Kros & $(\mathrm{X} 31)$, & TFT PS 160 ml. Kahverengi Bardak & $(\mathrm{X} 81)$, \\
\hline GN PS f 89,5 Bardak Kapağ1 Kros & $(\mathrm{X} 41)$, & TFT PP 180 ml. Beyaz Bardak & $(\mathrm{X} 91)$, \\
\hline GN PS f 160 Piknik Tabağ1 & $(\mathrm{X} 51)$, & TFT PP 300 ml. Desenli Bardak & (X101). \\
\hline
\end{tabular}

Plastik hammadde Welex makinesinde eritilerek levha haline getirilmektedir. Daha sonra bu levhalar GN ve TFT makinelerinde kalıp basma yoluyla işlenerek plastik tabak, bardak kapağı ve bardak ürünleri oluşturulmaktadır. Ürünlerin üretim süreci aşağıda Şekil 1 'de gösterilmiştir:

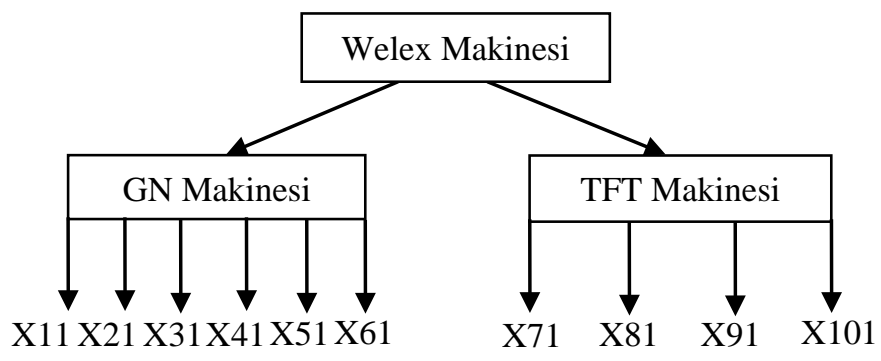

Şekil 1. Ürünlerin Üretim Süreci verilmiştir:

İncelenen 10 ürüne ve yarı mamule ilişkin maliyet bilgileri aşağıdaki tablolarda

Tablo 2. GN Makinesi Ürünleri Maliyet Tablosu

\begin{tabular}{|c|c|c|c|}
\hline \multicolumn{4}{|c|}{ GN 3021 Makine: PS f 73,5 Bardak Kapağı Maliyeti (X11 ürünü) } \\
\hline Günlük üretim & 373 kg/gün & \multicolumn{2}{|l|}{1,15 gr/birim } \\
\hline Çalışılan gün & 2,68 gün & \multicolumn{2}{|l|}{15 kalıp göz adedi } \\
\hline Aylık üretim & $1,000 \mathrm{~kg} / \mathrm{ay}$ & \multicolumn{2}{|l|}{15 çevrim/dk } \\
\hline Hammadde maliyeti & \multicolumn{3}{|c|}{$2,21 \mathrm{TL} / \mathrm{kg} \quad 15,53$ saatlik üretim } \\
\hline 1-Değişken giderler toplamı & $\begin{array}{c}\text { Pers. Say1s1 } \\
12\end{array}$ & $\begin{array}{c}\text { Aylık maliyet(TL) } \\
14.657,17\end{array}$ & $\begin{array}{c}\text { Maliyet (TL/kg) } \\
4,31\end{array}$ \\
\hline 2-Sabit giderler toplamı & 56 & $148.460,96$ & 0,57 \\
\hline \multicolumn{4}{|c|}{ GN 3021 Makine: PS f 80 Bardak Kapağı Maliyeti (X21 Ürünü) } \\
\hline Günlük üretim & $421 \mathrm{~kg} /$ gün & \multicolumn{2}{|l|}{$1,30 \mathrm{gr} / \mathrm{birim}$} \\
\hline Çalışılan gün & 2,37 gün & \multicolumn{2}{|l|}{15 kalıp göz adedi } \\
\hline Aylık üretim & $1,000 \mathrm{~kg} / \mathrm{ay}$ & \multicolumn{2}{|l|}{15 çevrim/dk } \\
\hline Hammadde maliyeti & \multicolumn{3}{|c|}{$2,21 \mathrm{TL} / \mathrm{kg} \quad 17,55$ saatlik üretim } \\
\hline 1-Değişken giderler toplamı & $\begin{array}{c}\text { Pers. Sayıs1 } \\
12\end{array}$ & $\begin{array}{c}\text { Aylık maliyet(TL) } \\
14.660,51\end{array}$ & $\begin{array}{c}\text { Maliyet (TL/kg) } \\
4,31\end{array}$ \\
\hline 2-Sabit giderler toplamı & 56 & $148.460,96$ & 0,57 \\
\hline \multicolumn{4}{|c|}{ GN 3021 Makine: PS f 80 Bardak Kapağı Kros Maliyeti (X31 Ürünü) } \\
\hline Günlük üretim & 358 kg/gün & \multicolumn{2}{|c|}{$1,30 \mathrm{gr} / \mathrm{birim}$} \\
\hline Çalışılan gün & 2,79 gün & \multicolumn{2}{|l|}{15 kalıp göz adedi } \\
\hline Aylık üretim & $1,000 \mathrm{~kg} / \mathrm{ay}$ & \multicolumn{2}{|l|}{15 çevrim/dk } \\
\hline Hammadde maliyeti & \multicolumn{3}{|c|}{$2,21 \mathrm{TL} / \mathrm{kg} \quad 14,92$ saatlik üretim } \\
\hline 1-Değişken giderler toplamı & \begin{tabular}{|c} 
Pers. Say1s1 \\
12
\end{tabular} & $\begin{array}{c}\text { Aylık maliyet(TL) } \\
14.731,63\end{array}$ & $\begin{array}{c}\text { Maliyet (TL/kg) } \\
4,38\end{array}$ \\
\hline 2-Sabit giderler toplamı & 56 & $148.460,96$ & 0,57 \\
\hline \multicolumn{4}{|c|}{ GN 3021 Makine: PS f 89,5 Bardak Kapağı Kros (X41 Ürünü) } \\
\hline Günlük üretim & 518 kg/gün & \multicolumn{2}{|l|}{$1,60 \mathrm{gr} / \mathrm{birim}$} \\
\hline Çalışılan gün & 1,93 gün & \multicolumn{2}{|l|}{15 kalıp göz adedi } \\
\hline
\end{tabular}




\begin{tabular}{|c|c|c|c|}
\hline Aylık üretim & $1,000 \mathrm{~kg} / \mathrm{ay}$ & \multicolumn{2}{|l|}{15 çevrim/dk } \\
\hline Hammadde maliyeti & \multicolumn{3}{|c|}{$2,21 \mathrm{TL} / \mathrm{kg} \quad 22$ saatlik üretim } \\
\hline 1-Değişken giderler toplamı & $\begin{array}{c}\text { Pers. Say1s1 } \\
12\end{array}$ & $\begin{array}{c}\text { Aylık maliyet(TL) } \\
14.658,37\end{array}$ & $\begin{array}{c}\text { Maliyet (TL/kg) } \\
4,31\end{array}$ \\
\hline 2-Sabit giderler toplamı & 56 & $148.460,96$ & 0,57 \\
\hline \multicolumn{4}{|c|}{ GN 3021 Makine: PS f 160 Piknik Tabağı Maliyeti (X51 Ürünü) } \\
\hline Günlük üretim & \multicolumn{2}{|l|}{655 kg/gün } & 3,50 gr/birim \\
\hline Çalışılan gün & \multicolumn{2}{|l|}{ 2,29 gün } & 10 kalıp göz adedi \\
\hline Aylık üretim & \multicolumn{2}{|l|}{$1,500 \mathrm{~kg} / \mathrm{ay}$} & 13 çevrim/dk \\
\hline Hammadde maliyeti & \multicolumn{3}{|c|}{$2,21 \mathrm{TL} / \mathrm{kg} \quad 27,30$ saatlik üretim } \\
\hline 1-Değișken giderler toplamı & $\begin{array}{c}\text { Pers. Sayis1 } \\
12\end{array}$ & $\begin{array}{c}\text { Aylık maliyet(TL) } \\
15.905,46\end{array}$ & $\begin{array}{c}\text { Maliyet (TL/kg) } \\
3,99\end{array}$ \\
\hline 2-Sabit giderler toplamı & 56 & $148.460,96$ & 0,61 \\
\hline \multicolumn{4}{|c|}{ GN 3021 Makine: PS f 205 Piknik Tabağı Maliyeti (X61 Ürünü) } \\
\hline Günlük üretim & $618 \mathrm{~kg} /$ gün & \multicolumn{2}{|l|}{ 5,50 gr/birim } \\
\hline Çalışılan gün & 2 gün & \multicolumn{2}{|l|}{6 kalıp göz adedi } \\
\hline Aylık üretim & $1,500 \mathrm{~kg} / \mathrm{ay}$ & \multicolumn{2}{|l|}{13 çevrim/dk } \\
\hline Hammadde maliyeti & \multicolumn{3}{|c|}{$2,21 \mathrm{TL} / \mathrm{kg} \quad 25,74$ saatlik üretim } \\
\hline 1-Değişken giderler toplamı & $\begin{array}{c}\text { Pers. Say1s1 } \\
12\end{array}$ & $\begin{array}{c}\text { Aylık maliyet(TL) } \\
15.795,80\end{array}$ & $\begin{array}{c}\text { Maliyet (TL/kg) } \\
3,91\end{array}$ \\
\hline 2-Sabit giderler toplamı & 56 & $148.460,96$ & 0,61 \\
\hline
\end{tabular}

Tablo 3. TFT Makinesi Ürünleri Maliyet Tablosu

\begin{tabular}{|c|c|c|c|}
\hline \multicolumn{4}{|c|}{ TFT Makine: PS 80 ml. Bardak Maliyeti (X71 Ürünü) } \\
\hline Günlük üretim & 259 kg/gün & \multicolumn{2}{|l|}{$1,80 \mathrm{gr} / \mathrm{birim}$} \\
\hline Çalışılan gün & 4,82 gün & \multicolumn{2}{|l|}{8 kalıp göz adedi } \\
\hline Aylık üretim & $1.250 \mathrm{~kg} / \mathrm{ay}$ & \multicolumn{2}{|l|}{25 çevrim/dk } \\
\hline 1-Değişken giderler toplamı & $\begin{array}{c}\text { Pers. Say1s1 } \\
6 \\
\end{array}$ & $\begin{array}{c}\text { Aylik maliyet(TL) } \\
9.459,58\end{array}$ & $\begin{array}{c}\text { Maliyet (TL/kg) } \\
3,12 \\
\end{array}$ \\
\hline 2-Sabit giderler toplamı & 56 & $149.462,76$ & 0,43 \\
\hline \multicolumn{4}{|c|}{ TFT Makine: PS 160 ml. Kahverengi Vending Bardak Maliyeti (X81 Ürünü) } \\
\hline Günlük üretim & $\begin{array}{l}1.063 \\
\text { kg/gün }\end{array}$ & \multicolumn{2}{|l|}{ 4,10 gr/birim } \\
\hline Çalışılan gün & 0,94 gün & \multicolumn{2}{|l|}{12 kalıp göz adedi } \\
\hline Aylık üretim & $1.000 \mathrm{~kg} / \mathrm{ay}$ & \multicolumn{2}{|l|}{15 çevrim/dk } \\
\hline 1-Değişken giderler toplamı & $\begin{array}{c}\text { Pers. Say1s1 } \\
6\end{array}$ & $\begin{array}{c}\text { Aylık maliyet(TL) } \\
6.782,39\end{array}$ & $\begin{array}{c}\text { Maliyet (TL/kg) } \\
1,17\end{array}$ \\
\hline 2-Sabit giderler toplam1 & 56 & $149.462,76$ & 0,46 \\
\hline \multicolumn{4}{|c|}{ TFT Makine: PP 180 ml. Beyaz Bardak Maliyeti (X91 Ürünü) } \\
\hline Günlük üretim & 553 kg/gün & \multicolumn{2}{|l|}{$2 \mathrm{gr} / \mathrm{birim}$} \\
\hline Çalışılan gün & 15,19 gün & \multicolumn{2}{|l|}{12 kalıp göz adedi } \\
\hline Aylık üretim & $\begin{array}{l}16.800 \\
\mathrm{~kg} / \mathrm{ay}\end{array}$ & \multicolumn{2}{|l|}{16 çevrim/dk } \\
\hline 1-Değişken giderler toplamı & $\begin{array}{c}\text { Pers. Say1s1 } \\
6 \\
\end{array}$ & $\begin{array}{c}\text { Aylık maliyet(TL) } \\
50.958,03 \\
\end{array}$ & $\begin{array}{c}\text { Maliyet (TL/kg) } \\
2,96\end{array}$ \\
\hline 2-Sabit giderler toplamı & 56 & $149.462,76$ & 0,46 \\
\hline \multicolumn{4}{|c|}{ TFT Makine: PP 300 ml Desenli Bardak Maliyeti (X101 Ürünü) } \\
\hline Günlük üretim & 292 kg/gün & \multicolumn{2}{|l|}{ 4,50 gr/birim } \\
\hline Çalışılan gün & 3,43 gün & \multicolumn{2}{|l|}{5 kalıp göz adedi } \\
\hline Aylık üretim & $1.000 \mathrm{~kg} / \mathrm{ay}$ & \multicolumn{2}{|l|}{9 çevrim/dk } \\
\hline 1-Değişken giderler toplamı & $\begin{array}{c}\text { Pers. Say1s1 } \\
6 \\
\end{array}$ & $\begin{array}{c}\text { Aylık maliyet(TL) } \\
8.799,10 \\
\end{array}$ & $\begin{array}{c}\text { Maliyet (TL/kg) } \\
3,18\end{array}$ \\
\hline 2-Sabit giderler toplamı & 56 & $149.462,76$ & 0,46 \\
\hline
\end{tabular}


Tablo 4. Welex Makinesi Levha Maliyet Tablosu

\begin{tabular}{|l|c|l|l|}
\hline Weleks Makine: PS Levha Maliyeti (Bardak+Tabak İçin) \\
\hline Günlük üretim & $5.000 \mathrm{~kg} /$ gün & & \\
\hline Çalışılan gün & 21 gün & & \\
\hline Aylı üretim & 102,500 kg/ay & & \\
\hline & Pers. Sayıs1 & Aylık maliyet (TL) & Maliyet (TL/kg) \\
1-Değişken giderler toplamı & 7 & $220.533,06$ & 2,15 \\
\hline 2-Sabit giderler toplamı & 56 & $178.267,08$ & 0,06 \\
\hline
\end{tabular}

Ürünlere ilişkin değişken ve sabit maliyetler dikkate alınarak tam maliyet sistemine göre belirlenen ürün kârları Tablo 5 ve 6'da gösterilmiştir.

Tablo 5. GN Makinesi Ürünleri Birim Kâr/Zarar Tablosu

\begin{tabular}{|c|c|c|c|c|c|c|}
\hline (TL/1.000birim) & (X11) & (X21) & (X31) & (X41) & (X51) & $(\mathrm{X61)}$ \\
\hline Bir ürün ağırlığI & $1,15 \mathrm{gr}$ & $1.30 \mathrm{gr}$ & $1,30 \mathrm{gr}$ & $1,60 \mathrm{gr}$ & $3,50 \mathrm{gr}$ & 5,50 \\
\hline 1.Değişken gid. & $5,12 \mathrm{TL}$ & $5,79 \mathrm{TL}$ & $5,89 \mathrm{TL}$ & $7,13 \mathrm{TL}$ & $14,45 \mathrm{TL}$ & 307 \\
\hline Hammadde mal & $2,67 \mathrm{TL}$ & $3,02 \mathrm{TL}$ & $3,02 \mathrm{TL}$ & $3,72 \mathrm{TL}$ & $8,13 \mathrm{TL}$ & $12,78 \mathrm{TL}$ \\
\hline Enerji & $0,47 \mathrm{TL}$ & $47 \mathrm{TL}$ & $56 \mathrm{TL}$ & $7 \mathrm{TL}$ & $082 \mathrm{TI}$ & 1367 \\
\hline Poşet & $0,12 \mathrm{TL}$ & $0,12 \mathrm{TL}$ & $0,12 \mathrm{TL}$ & $0,14 \mathrm{TL}$ & $0,21 \mathrm{TL}$ & $0,21 \mathrm{TL}$ \\
\hline Kutu & $0,17 \mathrm{TL}$ & $0,20 \mathrm{TL}$ & $0,20 \mathrm{TL}$ & $0,30 \mathrm{TL}$ & $0,62 \mathrm{TL}$ & $0,62 \mathrm{TL}$ \\
\hline Nakliye & $0,22 \mathrm{TL}$ & $0,26 \mathrm{TL}$ & & $0,40 \mathrm{TL}$ & $0,31 \mathrm{TL}$ & $0,49 \mathrm{TL}$ \\
\hline İşletme & $0,29 \mathrm{TL}$ & 0,3 & & & & $\mathrm{TL}$ \\
\hline rimi & $0,15 \mathrm{TL}$ & 0,2 & 0,2 & 0,2 & $\overline{T L}$ & $\mathrm{TL}$ \\
\hline Reklam & $03 \mathrm{TL}$ & 0 & 0,0 & $\overline{T L}$ & TL & TL \\
\hline Satıcı primi & $0,00 \mathrm{TL}$ & $0,01 \mathrm{TL}$ & $0,01 \mathrm{TL}$ & $0,01 \mathrm{TL}$ & $0,01 \mathrm{TL}$ & $0,02 \mathrm{TL}$ \\
\hline Direkt işçilik & $0,99 \mathrm{TL}$ & $0,12 \mathrm{TL}$ & $1,12 \mathrm{TL}$ & $1,38 \mathrm{TL}$ & $3,03 \mathrm{TL}$ & $4,76 \mathrm{TL}$ \\
\hline 2.Sabit gid. top & 0,66 TL & 0,75 TL & 0,75 TL & TL & TL & 3,40 TL \\
\hline giderleri & $0,12 \mathrm{TL}$ & & & & $\mathrm{TL}$ & $\mathrm{TL}$ \\
\hline Ücre & 0,0 & & & & & $\overline{T L}$ \\
\hline & $0,45 \mathrm{TL}$ & & & & & \\
\hline Kur fark $1+$ faiz & $0,03 \mathrm{TL}$ & $0,03 \mathrm{TL}$ & $0,03 \mathrm{TL}$ & $0,04 \mathrm{TL}$ & $0,09 \mathrm{TL}$ & $0,14 \mathrm{TL}$ \\
\hline Toplam n & $5,78 \mathrm{TL}$ & 6,54 TL & 6,64 TL & $8,05 \mathrm{TL}$ & TL & $25,70 \mathrm{TL}$ \\
\hline & 7,45 TL & 11,11 TL & 11,65 TL & $12,50 \mathrm{TL}$ & 16,75 TL & TL \\
\hline Kâr/zarar & 1,67 TL & 4,57 TL & $5,01 \mathrm{TL}$ & 4,45 TL & 0,14 TL &, 15 \\
\hline
\end{tabular}

Tablo 6. TFT Makinesi Ürünleri Birim Kâr/Zarar Tablosu

\begin{tabular}{|c|c|c|c|c|}
\hline (TL/1.000 birim) & (X71) & (X81) & (X91) & (X101) \\
\hline Bir ürün ağırlığı & $1.80 \mathrm{gr}$ & $4,10 \mathrm{gr}$ & $2,00 \mathrm{gr}$ & $4,50 \mathrm{gr}$ \\
\hline 1-Değişken gid.top. & $6 \mathrm{TL}$ & $5 \mathrm{TL}$ & $6,15 \mathrm{TL}$ & $14 \mathrm{TL}$ \\
\hline Hammadde maliyeti & $4,18 \mathrm{TL}$ & $1,34 \mathrm{TL}$ & $3,84 \mathrm{TL}$ & $8,64 \mathrm{TL}$ \\
\hline Enerji & $0,42 \mathrm{TL}$ & $0,47 \mathrm{TL}$ & $0,44 \mathrm{TL}$ & $1,89 \mathrm{TL}$ \\
\hline Poşet & $0,13 \mathrm{TL}$ & $0,15 \mathrm{TL}$ & $0,15 \mathrm{TL}$ & $0,21 \mathrm{TL}$ \\
\hline Kutu & $0,13 \mathrm{TL}$ & $0,17 \mathrm{TL}$ & $0,20 \mathrm{TL}$ & $0,41 \mathrm{TL}$ \\
\hline Nakliye & $0,27 \mathrm{TL}$ & $0,43 \mathrm{TL}$ & $0,34 \mathrm{TL}$ & $0,80 \mathrm{TL}$ \\
\hline İșletme malzemesi & $0,37 \mathrm{TL}$ & $0,84 \mathrm{TL}$ & $0,41 \mathrm{TL}$ & $0,92 \mathrm{TL}$ \\
\hline Bayi primi & $0,14 \mathrm{TL}$ & $0,32 \mathrm{TL}$ & $0,15 \mathrm{TL}$ & $0,27 \mathrm{TL}$ \\
\hline Reklam+fuar kat.gid. & $0,05 \mathrm{TL}$ & $0,11 \mathrm{TL}$ & $0,05 \mathrm{TL}$ & $0,27 \mathrm{TL}$ \\
\hline Satıcı primi & $0,01 \mathrm{TL}$ & $0,01 \mathrm{TL}$ & $0,01 \mathrm{TL}$ & $0,27 \mathrm{TL}$ \\
\hline Direkt işçilik & $0,46 \mathrm{TL}$ & $1,05 \mathrm{TL}$ & $0,56 \mathrm{TL}$ & $0,00 \mathrm{TL}$ \\
\hline 2-Sabit gid.top. & $1 \mathrm{TL}$ & $1,91 \mathrm{TL}$ & $0,93 \mathrm{TL}$ & $2,09 \mathrm{TL}$ \\
\hline Ücret giderleri & $0,21 \mathrm{TL}$ & $0,50 \mathrm{TL}$ & $0,24 \mathrm{TL}$ & $0,54 \mathrm{TL}$ \\
\hline
\end{tabular}




\begin{tabular}{|l|l|r|l|r|}
\hline Ücret dişı gid. & 0,10 TL & 0,34 TL & 0,17 TL & 0,38 TL \\
\hline Amortisman & 0,42 TL & 0,95 TL & 0,46 TL & 1,04 TL \\
\hline Kur fark1 ve faiz & 0,05 TL & 0,12 TL & 0,06 TL & 0,13 TL \\
\hline Toplam maliyet & $\mathbf{6 , 9 4 ~ T L}$ & $\mathbf{6 , 7 8}$ TL & $\mathbf{7 , 0 8}$ TL & 15,77 TL \\
\hline Satış fiyatı & $\mathbf{9 , 6 0}$ TL & $\mathbf{1 1 , 9 5 ~ T L}$ & $\mathbf{7 , 6 9}$ TL & $\mathbf{1 8 , 2 0}$ TL \\
\hline Kâr/zarar & $\mathbf{2 , 6 6 ~ T L}$ & $\mathbf{5 , 1 7}$ TL & $\mathbf{0 , 6 1}$ TL & $\mathbf{2 , 4 3}$ TL \\
\hline
\end{tabular}

\subsection{Verilerin Analizi}

İşletmede yapılan araştırmada, işletmenin üretim sürecinde kısıtın varolup olmadığı araştırma sorusuna (birinci araştırma sorusu) cevap vermek üzere kaynak yükü analizi yapılmıştır. Kaynak yükü analizi çerçevesinde, kaynakların mevcut kapasitesi ile talepleri karşılayabilmek için gereken kapasitelerini karşılaştırmak ve kapasite kullanım oranlarını tespit etmek suretiyle kısıtlar aşağıda tespit edilmiştir.

PS f 73,5 Bardak kapağı (X11 Ürünü): Aylık talep $1.500-2.500$ kg.

Şayet $2.500 \mathrm{~kg}$ ise, 1 birim bardak kapağ $1=1,15$ gr olduğundan

2.500.000 gr talep $=(2.500 .000$ gr $\div 1,15$ gr $) 2.173 .913$ birim bardak kapağ aylık talep söz konusu demektir. Kapasite (Makine sadece bu ürünü üretiyorsa) $=15$ birim/çevrim x 15 çevrim/dk $=225$ birim/dk

Aylı üretim miktarı $=225 \mathrm{birim} / \mathrm{dk}$ x $60 \mathrm{dk} / \mathrm{saat} \times 24$ saat $/$ gün $\times 30$ gün/ay $=9.720 .000$ birimdir.

Kapasite kullanım oranı $=$ Aylık talep $\div$ Aylık üretim $=2.173 .913$ birim $\div 9.720 .000$ birim $=\%$ 22,365

0,22365 x 30 gün/ay = 6,7095 gün/ay (talebi karş1lamak için ayda çalışılması gereken gün say1s1)

PS f 80 Bardak kapağı (X21 Ürünü): Aylık talep 1.000 - 2.500 kg.

Şayet $2.500 \mathrm{~kg}$ ise, 1 birim bardak kapağ $1=1,3$ gr olduğundan

2.500 .000 gr talep $=(2.500 .000$ gr $\div 1,3$ gr $) 1.923 .076$ birim bardak kapağı aylık talep söz konusu demektir.

Kapasite (Makine sadece bu ürünü üretiyorsa) = 15 birim/çevrim x 15 çevrim $/ \mathrm{dk}=225$ birim/dk

Aylık üretim miktarı $=225 \mathrm{birim} / \mathrm{dk} \times 60 \mathrm{dk} /$ saat $\times 24$ saat $/$ gün $\times 30$ gün/ay $=9.720 .000$ birim

Kapasite kullanım oranı $=$ Aylık talep $\div$ Aylık üretim $=1.923 .076$ birim $\div 9.720 .000$ birim $=\%$ 19,785

0,19785 x 30 gün/ay = 5,9354 gün/ay (talebi karş1lamak için ayda çalışılması gereken gün say1s1)

PS f 80 Bardak kapağı kros (X31 Ürünü): Aylık talep 1.000 - 1.800 kg.

Şayet $1.800 \mathrm{~kg}$ ise, 1 birim bardak kapağ $1=1,3$ gr olduğundan

1.800 .000 gr talep $=(1.800 .000$ gr $\div 1,3$ gr $) 1.384 .615$ birim bardak kapağ1 aylık talep söz konusu demektir.

Kapasite (Makine sadece bu ürünü üretiyorsa) = 15 birim/çevrim x 15 çevrim/dk = 225 birim/dk

Aylık üretim miktarı $=225 \mathrm{birim} / \mathrm{dk} \times 60 \mathrm{dk} /$ saat $\times 24$ saat $/$ gün $\times 30$ gün/ay $=9.720 .000$ birim 
Kapasite kullanım oran $1=$ Aylık talep $\div$ Aylık üretim $=1.384 .615$ birim $\div 9.720 .000$ birim $=$ $\% 14,245$

0,14245 x 30 gün/ay = 4,2735 gün/ay (talebi karş1lamak için ayda çalışılması gereken gün say1s1)

PS f 89,5 Bardak kapağı kros (X41 Ürünü): Aylık talep $1.800-2.000$ kg.

Şayet $2.000 \mathrm{~kg}$ ise, 1 birim bardak kapağ $1=1,6$ gr olduğundan

2.000.000 gr talep $=(2.000 .000$ gr $\div 1,6$ gr $) 1.812 .500$ birim bardak kapağı aylık talep söz konusu demektir.

Kapasite (Makine sadece bu ürünü üretiyorsa) = 15 birim/çevrim x 15 çevrim/dk $=225$ birim/dk

Aylı üretim miktarı $=225 \mathrm{birim} / \mathrm{dk} \times 60 \mathrm{dk} /$ saat $\times 24$ saat $/$ gün $\times 30$ gün/ay $=9.720 .000$ birim

Kapasite kullanım oran $1=$ Aylık talep $\div$ Aylık üretim $=1.812 .500$ birim $\div 9.720 .000$ birim $=$ $\% 18,647$

0,18647 x 30 gün/ay = 5,5941 gün/ay (talebi karşılamak için ayda çalışılması gereken gün say1s1)

PS f 160 Piknik tabağı (X51 Ürünü): Aylık talep $2.500-8.000$ kg.

Şayet $8.000 \mathrm{~kg}$ ise, 1 birim piknik tabağ $1=3,5$ gr olduğundan

8.000.000 gr talep $=(8.000 .000$ gr $\div 3,5$ gr $) 2.285 .714$ birim piknik tabağı aylık talep söz konusu demektir.

Kapasite (Makine sadece bu ürünü üretiyorsa) = 10 birim/çevrim x 13 çevrim $/ \mathrm{dk}=130$ birim/dk

Aylı üretim miktarı $=130 \mathrm{birim} / \mathrm{dk} \times 60 \mathrm{dk} /$ saat $\times 24$ saat $/$ gün $\times 30$ gün/ay $=5.616 .000$ birim

Kapasite kullanım oranı $=$ Aylık talep $\div$ Aylık üretim $=2.285 .714$ birim $\div 5.616 .000$ birim $=$ $\% 40,7$

0,407 x 30 gün/ay = 12,210 gün/ay (talebi karşılamak için ayda çalışılması gereken gün say1s1)

PS f 205 Piknik tabağı (X61 Ürünü): Aylık talep $2.500-6.000$ kg.

Şayet $6.000 \mathrm{~kg}$ ise, 1 birim piknik tabağ $1=5,5$ gr olduğundan

6.000 .000 gr talep $=(6.000 .000$ gr $\div 5,5$ gr $) 1.090 .909$ birim piknik tabağ aylık talep söz konusu demektir.

Kapasite (Makine sadece bu ürünü üretiyorsa) = 6 birim/çevrim x 13 çevrim/dk $=78 \mathrm{birim} / \mathrm{dk}$ Aylık üretim miktarı = 78 birim/dk x $60 \mathrm{dk} /$ saat x 24 saat $/$ gün x 30 gün/ay = $3.369 .600 \mathrm{birim}$ Kapasite kullanım oran $1=$ Aylık talep $\div$ Aylık üretim $=1.090 .909$ birim $\div 3.369 .600$ birim $=$ $\% 32,375$

0,32375 x 30 gün/ay = 9,7125 gün/ay (talebi karş1lamak için ayda çalışılması gereken gün say1s1)

PS 80 ml. Bardak (X71 Ürünü): Aylık talep $0-6.500 \mathrm{~kg}$.

$6.500 \mathrm{~kg}$ ise, 1 birim bardak $=1,8$ gr olduğundan

6.500 .000 gr talep $=(6.500 .000$ gr $\div 1,8$ gr $) 3.611 .111$ birim bardak aylık talep söz konusu demektir.

Kapasite (Makine sadece bu ürünü üretiyorsa) $=8$ birim/çevrim x 25 çevrim/dk $=200$ birim/dk

Aylı üretim miktarı $=200 \mathrm{birim} / \mathrm{dk} \times 60 \mathrm{dk} /$ saat $\times 24$ saat $/$ gün $\times 30$ gün/ay $=8.640 .000$ birim 
Kapasite kullanım oran $1=$ Aylık talep $\div$ Aylık üretim $=3.611 .111$ birim $\div 8.640 .000$ birim $=$ $\% 41,795$

0,41795 x 30 gün/ay = 12,538 gün/ay (talebi karş1lamak için ayda çalışılması gereken gün say1s1)

PS 160 ml. Kahverengi vending bardak (X81 Ürünü): Aylık talep $0-6.000 \mathrm{~kg}$.

Şayet $6.000 \mathrm{~kg}$ ise, 1 birim bardak $=4,10$ gr olduğundan

6.000 .000 gr talep $=(6.000 .000$ gr $\div 4,10$ gr $) 1.463 .414$ birim bardak aylık talep söz konusu demektir.

Kapasite (Makine sadece bu ürünü üretiyorsa) $=12$ birim/çevrim x 15 çevrim $/ \mathrm{dk}=180$ birim/dk

Aylı üretim miktarı $=180 \mathrm{birim} / \mathrm{dk}$ x $60 \mathrm{dk} /$ saat $\times 24$ saat $/$ gün x 30 gün/ay $=7.776 .000$ birim

Kapasite kullanım oran $1=$ Aylık talep $\div$ Aylık üretim $=1.463 .414$ birim $\div 7.776 .000$ birim $=$ $\% 18,819$

0,18819 x 30 gün/ay = 5,6458 gün/ay (talebi karşılamak için ayda çalışılması gereken gün sayis1)

PP 180 ml. Beyaz bardak (X91 Ürünü): Aylık talep $10.000-15.000$ kg.

Şayet $10.000 \mathrm{~kg}$ ise, 1 birim bardak $=2$ gr olduğundan

10.000.000 gr talep $=(10.000 .000$ gr $\div 2$ gr $) 5.000 .000$ birim bardak aylık talep söz konusu demektir.

Kapasite (Makine sadece bu ürünü üretiyorsa) = 12 birim/çevrim x 16 çevrim/dk = 192 birim/dk

Aylı üretim miktarı = $192 \mathrm{birim} / \mathrm{dk}$ x $60 \mathrm{dk} /$ saat $\times 24$ saat $/$ gün x 30 gün/ay $=8.294 .400$ birim

Kapasite kullanım oranı $=$ Aylık talep $\div$ Aylık üretim $=5.000 .000$ birim $\div 8.294 .400$ birim $=$ $\%$ 60,281

0,60281 x 30 gün/ay = 18,0844 gün/ay (talebi karşılamak için ayda çalış1lması gereken gün say1s1)

PP 300 ml. Desenli bardak (X101 Ürünü): Aylık talep $500-1.500$ kg.

Şayet $1.500 \mathrm{~kg}$ ise, 1 birim bardak $=4,5$ gr olduğundan

1.500 .000 gr talep $=(1.500 .000$ gr $\div 4,5$ gr $) 333.333$ birim bardak aylı talep söz konusu demektir.

Kapasite (Makine sadece bu ürünü üretiyorsa) = 5 birim/çevrim x 9 çevrim/dk $=45$ birim/dk

Aylı üretim miktarı $=45$ birim/dk x $60 \mathrm{dk} /$ saat x 24 saat $/$ gün x 30 gün/ay $=1.944 .000$ birim

Kapasite kullanım oran $1=$ Aylık talep $\div$ Aylık üretim $=333.333$ birim $\div 1.944 .000$ birim $=$ $\% 17,146$

0,17146 x 30 gün/ay = 5,1440 gün/ay (talebi karş1lamak için ayda çalışılması gereken gün say1s1)

Görülmektedir ki hem GN hem de TFT makinesi kapasite kısıtlı kaynaktır. Zira kapasite kullanım oranlarına bakıldığında, GN makinesinde \% 147, TFT makinesinde \% 138 kapasite kullanım oranı sözkonusu olup, her iki makinenin ürünlerle ilgili talepleri karşılamak için gereken kapasitesi, mevcut kapasitesini aşmaktadır.

İşletmenin ürün karması kararlarını geleneksel yöntemlere göre belirleyip belirlemedikleri araştırma sorusuna (ikinci araştırma sorusu) cevap vermek üzere yapılan incelemede üst yönetimle görüşülmüş ve ürün karması belirlenmediği tespit edilmiştir. İşletmenin temel hedefinin müşteri memnuniyeti olduğunu ve çoğu zaman birim kârlar 
dikkate alınmadan uzun vadede sağlayacağı fayda düşünülerek, her ne kadar düşük kârlılığa sahip de olsa, düşük kâr sağlayan ürün veya ürünlerin üretimine öncelik verilerek üretim yapılabildiği tespit edilmiştir. Öyle ki bazen müşteriler bir ürün siparişi verirken aynı anda kârlılığı düşük olan başka bir ürün siparişi de verebilmekte ve iki siparişini de aynı anda isteyebilmektedirler. Bu durumda işletme, kârlılığının düşük olduğunu gözetmeden diğer ürünü üretmek durumunda da kalabilmektedir. Özetle işletme, mevcut müşterilerin işletme ürünlerine bağlılığının ve dolayısıyla taleplerinin azalmamasını hedeflediğinden, birim kârı düşük ürün veya ürünler, kârı düşük de olsa üretim programına alınmakta, bu yüzden en uygun ürün karması belirlenememektedir. İşletmede en uygun ürün karması belirleme durumu söz konusu olduğunda ise birim kârların dikkate alınabileceği tespit edilmiş olup, birim kârlara göre ürün kârlılık sıralaması aşağıda Tablo 7'de gösterilmiştir. İşletmede en uygun ürün karması belirlenmek istendiğinde, birim kârlar ve kapasiteler dikkate alınarak bu sıralamaya göre kapasitenin elverdiği ölçüde üretim yapılabilecektir.

Tablo 7. Tam Maliyet Sistemine Göre Üretim Öncelikleri

\begin{tabular}{|l|l|l|c|}
\hline $\mathbf{1 .} \mathbf{X 8 1}=$ & 5,17 TL kâr & $\mathbf{6 .} \mathbf{X 1 0 1}=$ & 2,43 TL kâr \\
\hline $\mathbf{2} \mathbf{X} 31=$ & 5,01 TL kâr & $\mathbf{7 . X 1 1}=$ & 1,67 TL kâr \\
\hline $\mathbf{3 .} \mathbf{X 2 1}=$ & 4,57 TL kâr & $\mathbf{8 .} \mathbf{X 9 1}=$ & 0,61 TL kâr \\
\hline $\mathbf{4 .} \mathbf{X 4 1}=$ & 4,45 TL kâr & $\mathbf{9 .}$ X51 $=$ & 0,14 TL kâr \\
\hline $\mathbf{5 . X 7 1}=$ & 2,66 TL kâr & $\mathbf{1 0 .}$ X61 $=$ & $(0,15)$ TL zarar \\
\hline
\end{tabular}

İşletmede "FDM, KT ve her iki yöntemin birlikte kullanılması ile belirlenen ürün karmasının, geleneksel yöntemlere göre belirlenen ürün karmasından daha kârlı sonuçlar yaratıp yaratmadığı" araştırma sorusuna cevap vermek üzere, öncelikle FDM'e, ardından KT'e, daha sonra her iki yöntemin birlikte kullanılmasına göre saf tamsayılı programlama ile model kurulmuştur. Ardından çözüm algoritması uygun WINQSB ve MATLAB programları yardımıyla çözümlenerek ürün karmaları tespit edilmiştir. Daha sonra geleneksel yöntemlerden tam maliyet sistemine göre belirlenen birim kârlar dikkate alınarak model kurulmuş ve çözümlenerek ürün karması tespit edilmiştir. Son olarak, belirlenen ürün karmalarına göre kârlılık sonuçları karşılaştırılmıştır. FDM, KT ve her iki yöntemin birlikte kullanılmasına göre saf tamsayılı programlama ile belirlenecek model verilerinin analiz edilebilmesi için öncelikle faaliyet maliyetlerinin tespit edilmesi gerekmektedir. Her üç makine (Welex, GN ve TFT makineleri) için gerekli üretim faaliyetleri ve bunların maliyetleri işletmeden edinilen veriler doğrultusunda aşağıdaki gibi hesaplanmıştır:

Saf tamsayılı programlama ile modellerin kurulması için modellerde kullanılan notasyonlar aşağıda belirtilmiştir:

$\mathrm{i}=$ ürün indeksi (çeşidi)

1 : GN 3021 Makine PS f 73,5 Bardak Kapağ

2 : GN 3021 Makine PS f 80 Bardak Kapağ 1

3: GN 3021 Makine PS f 80 Bardak Kapağ 1 Kros

4 : GN 3021 Makine PS f 89,5 Bardak Kapağı Kros

5: GN 3021 Makine PS f 160 Piknik Tabağ 1

6: GN 3021 Makine PS f 205 Piknik Tabağ 1

7 : TFT Makine PS 80 ml. Bardak

8 : TFT Makine PS 160 ml. Kahverengi Vending Bardak

9 : TFT Makine PP 180 ml. Beyaz Bardak

10: TFT Makine PP 300 ml. Desenli Bardak 
$\mathrm{j}=$ Üretim faaliyet indeksi

1 : Welex Makinesi Faaliyeti (eriterek levha haline getirme)

2: GN Makinesi Faaliyeti (kalıp basma)

3 : TFT Makinesi Faaliyeti (kalıp basma)

4: GN Makinesinde İşgücü Toplama ve Paketleme Faaliyeti

5 : TFT Makinesinde İşgücü Toplama ve Paketleme Faaliyeti

$\mathrm{k}=$ Üretim seviyesi indeksi

$\mathrm{k}=1$ birim seviyesi

$\mathrm{k}=2$ parti seviyesi

q ij1 = 1.000 birim i ürünü üretmek için gerçekleştirilen $\mathrm{j}$ faaliyet sayısı

q ij2 = i. ürünü üretmek için gerçekleştirilen hazırlık faaliyet sayısı

pi $=\mathrm{i}$ ürününün fiyatı

$\mathrm{Pi}=\mathrm{i}$. ürün için birim kâr

$\mathrm{Qj}=\mathrm{j}$. faaliyetin kapasitesi

$\mathrm{Di}=\mathrm{i}$. ürün için pazar talebi

ci0 $=\mathrm{i}$. ürünün hammadde maliyeti

cjk $=\mathrm{j}$. faaliyetin k seviyesindeki birim maliyeti

cyci $=$ i. ürünün çevrim sayısi/dk

$\mathrm{st}=$ hazırlık zamanı $(\mathrm{dk})$

$\mathrm{Rjk}=$ yönetimin kontrolünde olan kapasite miktarı

$\mathrm{Njk}=$ yönetimin kontrolünde olmayan kapasite miktarı

$\mathrm{R} * \mathrm{jk}=$ yönetimin kontrolünde olan toplam kapasitenin üretimde kullanılan miktarı

$\mathrm{N} * \mathrm{jk}=$ yönetimin kontrolünde olmayan toplam kapasitenin üretimde kullanılan miktarı

c11 = Welex makinesinde $1 \mathrm{~kg}$ levha üretimi için ( 1 çevrim $=1$ faaliyet $)$ gerçekleştirilen faaliyetin maliyeti (hammadde hariç)

Elektrik + İşletme malzemesi + İşçilik + Amortisman + Bakım-onarım + Kalite güvence $=$ 28.794,48TL (102.500 kg)

$$
\frac{28.794,48 \mathrm{TL}}{102.500 \mathrm{~kg}}=0,2809 \mathrm{TL} / \mathrm{kg}
$$

c21 = GN makinesinde 1 çevrimde yapılan kalıp basma faaliyetinin birim maliyeti

Not: *Maliyet hesaplamada GN makinesi ve TFT makinesi çevrim sürelerinin ortalamas1 alınmıştır. Ortalama olarak çevrim süresi GN makinesinde 15, TFT makinesinde 16 alınmıştır.

*Makinelerden sorumlu tek bir operatör vardır. Dolayısıyla maliyeti her makineye eşit olarak yansıyacağından ürün karması kararını değiștirmeyecektir. Bu yüzden elimine edilmiştir.

Elektrik Gideri+ İşletme malzemesi $=652,35$ TL (2,68 gün için)

$652,35 \mathrm{TL} \div 2,68$ gün $=243,614 \mathrm{TL} /$ gün

$$
\frac{243,614 \mathrm{TL} / \text { gün }}{24 \text { saat / gün } x 60 \mathrm{dk} / \text { saat } x 15 \text { çevrim / dk }}=0,011 \mathrm{TL} / \text { çevrim }
$$

c31 = TFT makinesinde 1 çevrimde yapılan kalıp basma faaliyetinin birim maliyeti

Elektrik Gideri+ Işsletme malzemesi = 7.003,79 TL (15,19 gün için)

7.003,79 TL $\div$ 15,19 gün $=461,079 \mathrm{TL} /$ gün 
$\frac{461,079 \mathrm{TL} / \text { gün }}{24 \text { saat / gün } \times 60 \mathrm{dk} / \text { saat } \times 16 \text { çevrim/dk}}=0,02 \mathrm{TL} /$ çevrim c41 = GN makinesinde işgücü toplama ve paketleme faaliyetinin birim maliyeti Ambalaj gideri+ İşçilik = 1.047,27 TL (2,68 gün için)

$1.047,27 \mathrm{TL} \div 2,68$ gün $=390,77 \mathrm{TL} /$ gün

$\frac{390,77 \mathrm{TL} / \text { gün }}{24 \text { saat / gün } \times 60 \mathrm{dk} / \mathrm{saat} \times 15 \text { çevrim/dk}}=0,0181 \mathrm{TL} /$ çevrim

1 çevrimde 15 birim üretilmektedir. Dolayısıyla; 0,0181 TL/çevrim $\div 15$ birim/çevrim = $0,0012 \mathrm{TL} / \mathrm{birim}$

0,0012 TL/birim x $10 \mathrm{birim} /$ paketleme $=0,012 \mathrm{TL} /$ paketleme olmaktadır .

c51 = TFT makinesinde işgücü toplama ve paketleme faaliyetinin birim maliyeti

Ambalaj gideri + İşçilik $=5.441,28 \mathrm{TL}(15,19$ gün için $)$

$5.441,28 \mathrm{TL} \div 15,19$ gün $=358,215 \mathrm{TL} /$ gün

$\frac{358,215 \mathrm{TL} / \text { gün }}{24 \text { saat / gün } x 60 \mathrm{dk} / \mathrm{saat} \times 16 \text { çevrim/dk}}=0,0155 \mathrm{TL} /$ çevrim

1 çevrimde 12 birim üretilmektedir. Dolayısıyla; 0,0155 TL/çevrim $\div 12$ birim/çevrim = $0,00129 \mathrm{TL} / \mathrm{birim}$

0,00129 TL/birim x $100 \mathrm{birim} /$ paket $=0,129 \mathrm{TL} /$ paketleme olmaktadır.

$\mathrm{c} 12=$ Welex makinesinde hazırlık maliyeti $=0$

c22 $=$ GN makinesinde hazırlık faaliyeti maliyeti

1 hazırlık faaliyeti $=4$ saat $(240 \mathrm{dk})$

Not: paketlemeci hazırlık faaliyetini gerçekleştiriyor olarak dikkate alınmıştır.

Paketlemeci ücreti (aylık) $=7.995,60 \mathrm{TL}$

$\frac{7.995,60 \text { TL / ay }}{30 \text { gün / ay x } 24 \text { saat / gün }}=11,105$ TL / saat

11,105 TL/saat x 4 saat/hazırlık=44,42 TL/hazırlık

c32 $=$ TFT makinesinde hazırlik faaliyeti maliyeti

1 hazırlık faaliyeti $=4$ saat $(240 \mathrm{dk})$

Paketlemeci ücreti $($ aylık $)=2.665,20 \mathrm{TL}$

$\frac{2.665,20 \text { TL / ay }}{30 \text { gün / ay x } 24 \text { saat / gün }}=3,702 \mathrm{TL} /$ saat

$3,702 \mathrm{TL} /$ saat $\mathrm{x} 4 \mathrm{saat} /$ hazırlık $=14,807 \mathrm{TL} /$ hazırlık

Aylık kapasiteler aşağıdaki gibidir:

Not: Analiz döneminde makinelerin arızalanmadan, durmadan çalıştığg varsayılmaktadır.

$\mathrm{Q} 11=150.000 \mathrm{~kg} / \mathrm{ay}$

Q21 ve Q31 = $43.200 \mathrm{dk} / \mathrm{ay}$

say1s1)

Q41 = 900.000 paketleme/ay $\quad$ (GN - İşgücü toplama ve paketleme aylık faaliyet sayısı) 300.000 birim/gün $\div 10$ birim/ paketleme $=30.000$ paketleme/gün

30.000 paketleme /gün x 30 gün/ay $=900.000$ paketleme/ay

Q51 = 90.000 paketleme /ay $\quad$ (TFT - İşgücü toplama ve paketleme aylık faaliyet sayıs1)

Not: Welex makinesinde $1 \mathrm{~kg}$ bir çevrim kabul edilmiştir. 
İşletmede 8 saatlik 3 vardiya ile çalışılmaktadır.

3.203,85 TL/ay $\div 3$ kişi/ay $=1.067,95$ TL/kişi (kişi başına aylık ücret)

$1.067,95 \mathrm{TL} / \mathrm{kişi} \div 30$ gün $=35,5983 \mathrm{TL} /$ gün (kişi başına günlük ücret)

35,5983 TL/gün $\div 8 \mathrm{saat} /$ gün x $60 \mathrm{dk} / \mathrm{saat}=0,0741361 \mathrm{TL} / \mathrm{dk}$ (kişi başına dakika ücreti)

$0,0741361 \mathrm{TL} / \mathrm{dk} \div 15$ çevrim/dk $=0,005 \mathrm{TL} /$ çevrim (işçinin çevrim başına ücreti)

Her ürüne ilişkin hammadde maliyeti (ci0) hesaplanışı aşağıdaki gibidir:

X11 için = Aylık Ham. Mal. $\div$ Aylık Üretim $(\mathrm{kg})=2.322,8 \mathrm{TL} \div 1.000 \mathrm{~kg}=2,3228 \mathrm{TL} / \mathrm{kg}$ ci0 $=1.000$ gr 2,3228 TL ise $1,3 \mathrm{gr}=2,3228 \times 1,15 \div 1.000=0,00267122 \mathrm{TL} / \mathrm{birim}$ 1.000 birim için 2,67 TL/1.000 birim

X21 için = Aylık Ham. Mal. $\div$ Aylık Üretim $(\mathrm{kg})=2.322,8 \mathrm{TL} \div 1.000 \mathrm{~kg}=2,3228 \mathrm{TL} / \mathrm{kg}$ ci0 $=1.000$ gr $2,3228 \mathrm{TL}$ ise $1,3 \mathrm{gr}=2,3228 \times 1,3 \div 1.000=0,00301964 \mathrm{TL} / \mathrm{birim}$

1.000 birim için 3,02 TL/1.000 birim

X31 için = Aylık Ham. Mal. $\div$ Aylık Üretim $(\mathrm{kg})=2.322,8 \mathrm{TL} \div 1.000 \mathrm{~kg}=2,3228 \mathrm{TL} / \mathrm{kg}$ ci0 $=1.000$ gr 2,3228 TL ise 1,3 gr= 2,3228 x 1,3 $\div 1.000=0,00301964 \mathrm{TL} / \mathrm{birim}$

1.000 birim için 3,02 TL/1.000 birim

X41 için = Aylık Ham. Mal. $\div$ Aylık Üretim $(\mathrm{kg})=2.322,8 \mathrm{TL} \div 1.000 \mathrm{~kg}=2,3228 \mathrm{TL} / \mathrm{kg}$ ci0 $=1.000$ gr 2,3228 TL ise $1,3 \mathrm{gr}=2,3228 \times 1,6 \div 1.000=0,00371648 \mathrm{TL} / \mathrm{birim}$

1.000 birim için 3,72 TL/1.000 birim

X51 için = Aylık Ham. Mal. $\div$ Aylık Üretim $(\mathrm{kg})=3.484,2 \mathrm{TL} \div 1.500 \mathrm{~kg}=3,3228 \mathrm{TL} / \mathrm{kg}$ ci0 $=1.000$ gr 2,3228 TL ise 3,5 gr $=2,3228 \times 3,5 \div 1.000=0,0081298 \mathrm{TL} / \mathrm{birim}$ 1.000 birim için 8,13 TL/1.000 birim

X61 için = Aylık Ham. Mal. $\div$ Aylık Üretim $(\mathrm{kg})=3.484,2 \mathrm{TL} \div 1.500 \mathrm{~kg}=2,3228 \mathrm{TL} / \mathrm{kg}$ ci0 $=1.000$ gr 2,3228 TL ise 5,5 gr $=2,3228 \times 5,5 \div 1.000=0,0127754 \mathrm{TL} / \mathrm{birim}$

1.000 birim için 12,78 TL/1.000 birim

X71 için = Aylık Ham. Mal. $\div$ Aylık Üretim $(\mathrm{kg})=2.684,12 \mathrm{TL} \div 1.250 \mathrm{~kg}=2,147296$ $\mathrm{TL} / \mathrm{kg}$

ci0 $=1.000$ gr 2,147296 TL ise $1,8 \mathrm{gr}=2,147296 \times 1,8 \div 1.00=0,00418 \mathrm{TL} / \mathrm{birim}$

1.000 birim için 4,18 TL/1.000 birim

X81 için = Aylık Ham. Mal. $\div$ Aylık Üretim $(\mathrm{kg})=326,66 \mathrm{TL} \div 1.000 \mathrm{~kg}=0,32666 \mathrm{TL} / \mathrm{kg}$ ci0 $=1.000$ gr 0,32666 TL ise 4,1 gr=0,32666 x 4,1 $\div 1.000=0,001339306 \mathrm{TL} / \mathrm{birim}$

1.000 birim için 1,34 TL/1.000 birim

X91 için = Aylık Ham. Mal. $\div$ Aylık Üretim $(\mathrm{kg})=32.247,14 \mathrm{TL} \div 16.800 \mathrm{~kg}=1,9195$ $\mathrm{TL} / \mathrm{kg}$

ci0 $=1.000$ gr 1,9195 TL ise 2 gr $=1,9195 \times 2 \div 1.000=0,003839$ TL/birim

1.000 birim için 3,84 TL/1.000 birim

X101 için $=$ Aylı Ham. Mal. $\div$ Aylı Üretim $(\mathrm{kg})=1.919,47 \mathrm{TL} \div 1.000 \mathrm{~kg}=1,91947$ $\mathrm{TL} / \mathrm{kg}$

ci0 $=1.000$ gr $1,91947 \mathrm{TL}$ ise $4,5 \mathrm{gr}=1,91947 \times 4,5 \div 1.000=0,008638 \mathrm{TL} / \mathrm{birim}$

1.000 birim için 8,64 TL/1.000 birim

Faaliyet miktarlarının qijk hesaplanışı ise aşağıdaki gibidir:

qi11 (Welex makinesi eriterek levha haline getirme faaliyet sayısı): Her bir ürün için birim gram ağırlığına eşittir.

qi21 (GN makinesi kalıp basma faaliyet sayısı)

$\mathrm{X} 11$ ürünü için $=1.000 \mathrm{birim} / 15$ birim(kalıp göz adedi $)=66,66$ faaliyet sayıs1

X21 ürünü için $=1.000$ birim/ 15 birim(kalıp göz adedi $)=66,66$ faaliyet sayıs1 
X31 ürünü için $=1.000$ birim/ 15 birim(kalıp göz adedi $)=66,66$ faaliyet sayıs1 $X 41$ ürünü için $=1.000$ birim/ 15 birim(kalıp göz adedi $)=66,66$ faaliyet sayıs1 X51 ürünü için $=1.000 \mathrm{birim} / 10 \mathrm{birim}(\mathrm{kalıp}$ göz adedi $)=100$ faaliyet sayıs X61 ürünü için $=1.000$ birim $/ 6$ birim (kalıp göz adedi $)=166,66$ faaliyet sayıs1 $X 71$ ürünü için $=0$ birim $/ 8$ birim(kalıp göz adedi) $=0$ faaliyet sayısı $X 81$ ürünü için $=0$ birim/ 12 birim(kalıp göz adedi $)=0$ faaliyet sayıs1 $X 91$ ürünü için $=0 \mathrm{birim} / 12$ birim(kalıp göz adedi $)=0$ faaliyet sayıs1 $\mathrm{X} 101$ ürünü için $=0 \mathrm{birim} / 5 \mathrm{birim}(\mathrm{kalıp}$ göz adedi) $=0$ faaliyet sayısı qi31 (TFT makinesi kalıp basma faaliyet sayısı)

X11 ürünü için $=0$ birim/ 15 birim(kalıp göz adedi $)=0$ faaliyet sayısı $\mathrm{X} 21$ ürünü için $=0$ birim/ 15 birim(kalıp göz adedi $)=0$ faaliyet sayıs1 $\mathrm{X} 31$ ürünü için $=0 \mathrm{birim} / 15 \mathrm{birim}($ kalıp göz adedi $)=0$ faaliyet sayıs1 $\mathrm{X} 41$ ürünü için $=0 \mathrm{birim} / 15 \mathrm{birim}(\mathrm{kalıp}$ göz adedi $)=0$ faaliyet sayısı $X 51$ ürünü için $=0$ birim/ 10 birim(kalıp göz adedi $)=0$ faaliyet sayıs1 X61 ürünü için $=0$ birim $/ 6$ birim(kalıp göz adedi $)=0$ faaliyet sayısı X71 ürünü için $=1.000$ birim $/ 8$ birim(kalıp göz adedi $)=125$ faaliyet sayısı X81 ürünü için $=1.000$ birim $/ 12$ birim $($ kalıp göz adedi $)=83,33$ faaliyet sayıs1 X91 ürünü için $=1.000 \mathrm{birim} / 12 \mathrm{birim}($ kalıp göz adedi $)=83,33$ faaliyet sayıs1 $\mathrm{X} 101$ ürünü için $=1.000 \mathrm{birim} / 5 \mathrm{birim}(\mathrm{kalıp}$ göz adedi $)=200$ faaliyet sayıs1 qi41 (GN makinesi toplama ve paketleme faaliyet sayıs1)

GN makinesi ürünleri 100 birimlik paketler halinde toplanmaktadır. Dolayısıyla GN makinesi ürünleri için faaliyet sayısı 100 olacaktır.

X11 ürünü için $=100$ faaliyet sayıs1 X21 ürünü için $=100$ faaliyet sayıs1 X31 ürünü için $=100$ faaliyet sayısı X41 ürünü için $=100$ faaliyet sayısı X51 ürünü için $=100$ faaliyet sayısı X61 ürünü için $=100$ faaliyet sayısı X71 ürünü için $=0$ faaliyet sayıs1 X81 ürünü için $=0$ faaliyet sayıs1 X91 ürünü için $=0$ faaliyet sayıs1 qi51 (TFT makinesi toplama ve paketleme faaliyet sayıs1)

TFT makinesi ürünleri 10 birimlik paketler halinde toplanmaktadır. Dolayısıyla TFT makinesi ürünleri için faaliyet sayısı 10 olacaktır.

$\mathrm{X} 11$ ürünü için $=0$ faaliyet sayıs 1

X61 ürünü için $=0$ faaliyet sayısı

X21 ürünü için $=0$ faaliyet sayıs1

X71 ürünü için $=10$ faaliyet sayısı

X31 ürünü için $=0$ faaliyet sayıs1

X81 ürünü için $=10$ faaliyet sayısı

$\mathrm{X} 41$ ürünü için $=0$ faaliyet sayısı

X51 ürünü için $=0$ faaliyet sayısı

X91 ürünü için $=10$ faaliyet sayısı

X101 ürünü için $=10$ faaliyet sayıs1

Sirasıyla FDM, KT ve Entegre modele göre saf tamsayılı programlama ile modellerin kurulması ve bilgisayar programları aracılığıyla (WinQSB ve MATLAB) çözüm sonucu aşağıda gösterilmiştir (modellerin oluşumunda Kee ve Schmidth'in önerdikleri model temel alınmış, işletmeye uygun olarak tasarlanmış ve geliştirilmiştir):

FDM'e göre ürün karması modeli aşağıdaki gibi oluşturulmuştur:

Mak. Z $=\sum_{i}\left(p_{i}-c_{i 0}\right) X_{i 1}-\sum_{i, j, k} c_{j k} q_{i j k} X_{i k}$ 
Kisitlar:

$\sum_{i} X_{i 1} q_{i 11} \leq Q_{11}$

(Welex Makinesi kapasite k1sitı)

$\sum_{i} \frac{X_{i 1} q_{i j 1}}{c y c_{i}}+s t \sum_{i} X_{i 2} q_{i j 2} \leq Q_{j 1}$

$\mathrm{j}=2,3$

(GN ve TFT Mak. kapasite kısıt1)

$\sum_{i} X_{i 1} q_{i j 1}+\sum_{i} X_{i 2} q_{i j 2} \leq Q_{j 1}$

$\mathrm{j}=4,5$

(GN ve TFT Mak. işgücü kısıtı)

$X_{i 1} \leq D_{i} X_{i 2} \rightarrow X_{i 1}-D_{i} X_{i 2} \leq 0$

$\mathrm{i}=1-10$

(Talep kisit1)

$X_{i 1} \geq 0$

(Negatif olmama koşulu)

$X_{i 2}=0$ veya 1

(İkili değişken olma koşulu)

Modelin verilerinin WinQSB'de doğrusal ve tamsayılı programlama yardımı ile çözümlenmesi ile belirlenen ürün karması sonucu Tablo 8'de gösterilmiştir.

Tablo 8. FDM'e Göre Ürün Karmas1

\begin{tabular}{|l|c|l|c|}
\hline $\mathbf{X 1 1}($ birim) $=$ & 0 & $\mathbf{X 6 1}($ birim) $=$ & 129 \\
\hline $\mathbf{X 2 1}($ birim) $=$ & 1.923 & $\mathbf{X 7 1}($ birim) $=$ & 3.611 \\
\hline $\mathbf{X 3 1}($ birim) $=$ & 1.385 & $\mathbf{X 8 1}$ (birim) $=$ & 1.463 \\
\hline $\mathbf{X 4 1}$ (birim) $=$ & 1.813 & $\mathbf{X 9 1}$ (birim) $=$ & 1.724 \\
\hline X51 (birim) $=$ & 2.286 & $\mathbf{X 1 0 1}($ birim) $=$ & 333 \\
\hline
\end{tabular}

KT'e göre ürün karması modeli aşağıdaki gibi oluşturulmuştur:

Mak. Z $=\sum_{i}\left(p_{i}-c_{i 0}\right) X_{i 1}-\sum_{i, j, k} c_{i j k} Q_{j, k}$

Kisitlar:

$\sum_{i} X_{i 1} q_{i 11} \leq Q_{11}$

(Welex Makinesi kapasite kısıtı)

$\sum_{i} \frac{X_{i 1} q_{i j 1}}{c y c_{i}}+s t \sum_{i} X_{i 2} q_{i j 2} \leq Q$

$j=2,3$

(GN ve TFT Mak.kapasite kısitı)

$\sum_{i} X_{i 1} q_{i j 1}+\sum_{i} X_{i 2} q_{i j 2} \leq Q_{j 1}$

$\mathrm{j}=4,5$

(GN ve TFT Mak. işgücü kısıtı)

$X_{i 1} \leq D_{i} X_{i 2} \rightarrow X_{i 1}-D_{i} X_{i 2} \leq 0$

$\mathrm{i}=1-10$

(Talep kisit1)

$X_{i 1} \geq 0$

(Negatif olmama koşulu)

$X_{\text {i2 }}=0$ veya 1

(İkili değişken olma koşulu)

Modelin verilerinin WinQSB'de doğrusal ve tamsayılı programlama yardımı ile çözümlenmesi ile belirlenen ürün karması sonucu Tablo 9'da gösterilmiştir.

Tablo 9. KT’e Göre Ürün Karmas1

\begin{tabular}{|l|c|l|c|}
\hline $\mathbf{X 1 1}($ birim) $=$ & 374 & $\mathbf{X 6 1}($ birim) $=$ & 0 \\
\hline X21 (birim) $=$ & 1.923 & $\mathbf{X 7 1}$ (birim) $=$ & 3.611 \\
\hline X31 (birim) $=$ & 1.385 & $\mathbf{X 8 1}$ (birim) $=$ & 1.463 \\
\hline $\mathbf{X 4 1}($ birim) $=$ & 1.813 & $\mathbf{X 9 1}$ (birim) $=$ & 3.245 \\
\hline X51 (birim) $=$ & 2.285 & $\mathbf{X 1 0 1}$ (birim) $=$ & 0 \\
\hline
\end{tabular}

FDM ve KT'nin birlikte kullanılmasına göre ürün karması modeli (Entegre model); $Q_{j k}=N_{j k}+R_{j k}$ olduğu için, model aşağıdaki gibi oluşturulmaktadır; 
Mak. Z $=\sum_{i}\left(p_{i}-c_{i 0}\right) X_{i 1}-\sum_{i, j, k} c_{i j k}\left(N_{j k}+R_{j k}^{*}\right)$

Kisitlar:

$\sum_{i} X_{i 1} q_{i 11}-N_{11}^{*}-R_{11}^{*}=0$

(Welex Makinesi kapasite kısıt1)

$\sum_{i} \frac{X_{i 1} q_{i j 1}}{c y c_{i}}+s t \sum_{i} X_{i 2} q_{i j 2}-N_{j 1}^{*}-R_{j 1}^{*}=0$

$\mathrm{j}=2,3$ (GN ve TFT Mak. kapasite kısıtı)

$\sum_{i} X_{i 1} q_{i j 1}+\sum_{i} X_{i 2} q_{i j 2}-N_{j 1}^{*}-R_{j 1}^{*}=0$

$\mathrm{j}=4,5$ (GN ve TFT Mak. işgücü kısıtı)

$N_{j k}^{*} \leq N_{j k}$

(Yönetim kont. olmayan kap. kısıtı)

$R_{j k}^{*} \leq R_{j k}$

$X_{i 1} \leq D_{i} X_{i 2} \rightarrow X_{i 1}-D_{i} X_{i 2} \leq 0$ i $=1-10$

(Yönetim kont. olan kap. kısıtı)

$X_{i 1} \geq 0$

(Talep kisıtı)

(Negatif olmama koşulu)

$X_{i 2}=0$ veya 1

(İkili değişken olma koşulu)

Modelin verileri WinQSB'de doğrusal ve tamsayılı programlama programına girilmiş ancak çok fazla değişken olduğundan WinQSB'de doğrusal ve tamsayılı programlama programının çözüm algoritması modeli çözmek için yeterli olamamıştır. Bu yüzden daha karmaşık problemleri çözebilen MATLAB'den yararlanılmış, veriler MATLAB programına girilerek çözüm sonucu elde edilmiştir. Modelin verilerinin MATLAB programı yardımı ile çözümlenmesi ile belirlenen ürün karması sonucu Tablo 10’ da gösterilmiştir.

Tablo 10. FDM ve KT'nin Birlikte Kullanılması ile Belirlenen Ürün Karması

\begin{tabular}{|l|c|l|c|}
\hline $\mathbf{X 1 1}($ birim) $=$ & 0 & $\mathbf{X 6 1}($ birim) $=$ & 145 \\
\hline $\mathbf{X 2 1}($ birim) $=$ & 1.923 & $\mathbf{X 7 1}($ birim) $=$ & 3.611 \\
\hline $\mathbf{X 3 1}($ birim) $=$ & 1.385 & $\mathbf{X 8 1}($ birim) $=$ & 1.463 \\
\hline $\mathbf{X 4 1}($ birim) $=$ & 1.813 & $\mathbf{X 9 1}($ birim) $=$ & 3.262 \\
\hline X51 (birim) $=$ & 2.286 & $\mathbf{X 1 0 1}($ birim) $=$ & 0 \\
\hline
\end{tabular}

İşletmede birim kârlar dikkate alınarak ürün karması belirlenmek istediğinde, daha önce Tablo 7'de belirtilen kârlılık sıralaması dikkate alınmak suretiyle kapasite elverene kadar ürün üretilecektir. Ancak bunun elle çözülmesi oldukça güç olacağından, saf tamsayılı programlama ile aynı kısıtlar dikkate alınarak model kurulduğunda ve WinQSB yardımıyla çözümlendiğinde elde edilen sonuç aşağıda Tablo 11'de gösterilmiştir.

Mak. $\mathrm{Z}=\sum_{i} P_{i} X_{i 1}$

Kisitlar:

$\sum_{i} X_{i 1} q_{i 11} \leq Q_{11}$

(Welex Makinesi kapasite kısıtı)

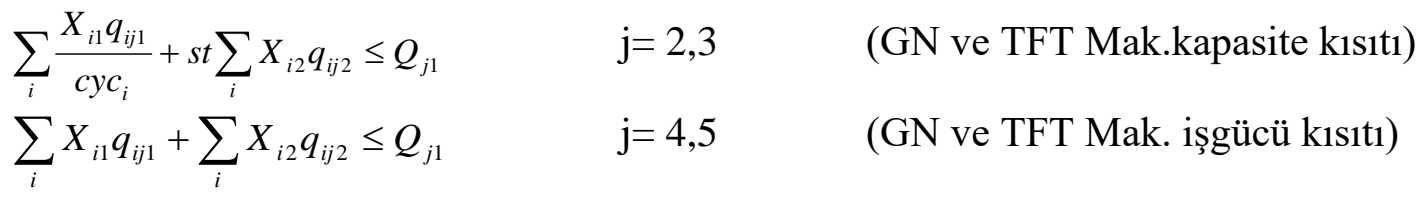




$$
\begin{aligned}
& X_{i 1} \leq D_{i} X_{i 2} \rightarrow X_{i 1}-D_{i} X_{i 2} \leq 0 \quad \mathrm{i}=1-10 \quad \text { (Talep kısıt1) } \\
& X_{i 1} \geq 0 \\
& \text { (Negatif olmama koşulu) } \\
& X_{i 2}=0 \text { veya } 1
\end{aligned}
$$

Tablo 11. Tam Maliyet Sistemine Göre Belirlenen Ürün Karmas1

\begin{tabular}{|l|c|l|c|}
\hline $\mathbf{X 1 1}($ birim) $=$ & 2.174 & $\mathbf{X 6 1}($ birim) $=$ & 0 \\
\hline $\mathbf{X 2 1}($ birim) $=$ & 1.923 & $\mathbf{X 7 1}($ birim) $=$ & 3.611 \\
\hline $\mathbf{X 3 1}$ (birim) $=$ & 1.385 & $\mathbf{X 8 1}$ (birim) $=$ & 1.463 \\
\hline $\mathbf{X 4 1}$ (birim) $=$ & 1.813 & $\mathbf{X 9 1}$ (birim) $=$ & 0 \\
\hline X51 (birim) $=$ & 0 & $\mathbf{X 1 0 1}$ (birim) $=$ & 333 \\
\hline
\end{tabular}

\section{BULGULARIN DEĞERLENDİRILMESI}

İşletmede "kısıtın var olup olmadı̆̆g” sorusunu cevaplamak üzere kaynak yükü analizi yapılmış ve sonucunda çoklu kısıt olduğu tespit edilmiştir. Zira talepleri karşılamak için GN makinesi kapasite kullanım oranı \% 147, TFT makinesi kapasite kullanım oranı ise \% 138 olarak tespit edilmiştir. Sonuç olarak her iki makinenin de mevcut kapasitesi, talepleri karşılamak için gereken kapasitelerinin gerisinde olduğundan her iki makine de kısıtlı kaynaktır.

İşletmede “ürün karması belirlemede geleneksel yöntemlerin kullanılıp kullanılmadığgı" sorusunu cevaplamaya ilişkin yapılan araştırmada, temel hedeflerinin müşteri memnuniyeti olduğu, bu yüzden de müşteri taleplerinin azalmaması için ürünün kârı düşük de olsa üretim programına alınarak üretildiği tespit edilmiştir. Ancak ürün karması belirleme durumu söz konusu olursa neyi dikkate alacakları sorusuna verilen cevap birim kârlardır. Yani işletmede ürün karması belirleme durumunda tam maliyet sistemine göre belirlenen birim kârların dikkate alınacağı tespit edilmiştir. İşletme için birim kârlar dikkate alınarak ürün karması teknik olarak elle hesaplanabiliyorsa da bu çok güç olduğundan araştırmada tam maliyet sistemine göre saf tamsayılı programlama modeli yardımıyla ürün karması tespit edilmiştir. Bu doğrultuda işletmede kapasiteler incelenerek belirlenen kısıtlar ve birim kârlar

\begin{tabular}{|c|c|}
\hline $\begin{array}{l}\text { Satışlar }(7,45 \times 2.174+11,11 \times 1.923+11,65 \times 1.385+12,50 \times 1.813+16,75 \times 0+25,55 \times 1 \\
0+9,60 \times 3.611+11,95 \times 1.463+7,69 \times 0+18,20 \times 333\end{array}$ & $134.567,63$ \\
\hline $\begin{array}{l}\text { (-) Değişken Gid.(5,12 × } 2.174+5,79 \times 1.923+5,89 \times 1.385+7,13 \times 1.813+14,45 \times 0+ \\
22,30 \times 0+6 \times 3.611+5 \times 1.463+6,15 \times 0+14 \times 333)\end{array}$ & $(76.992,39)$ \\
\hline Katk1 Pay1 & $57.575,24$ \\
\hline (-) Sabit Gid. $(150.000 \times 0,2809+43.200 \times 0,01 \times 15+43.200 \times 0,02 \times 16)$ & $(35.371,38)$ \\
\hline Kâr & $22.203,86$ \\
\hline
\end{tabular}
dikkate alınarak ürün karması belirlemek üzere model kurulmuş ve çözümlenmiştir. Sonuç olarak geleneksel tam maliyet sistemine göre elde edilen kâr aşağıda Tablo 12'de gelir tablosunda hesaplanmıştır.

Tablo 12. Geleneksel Yönteme Göre Ürün Karması Kârl11ı̆̆1 (TL/1.000 birim) 
FDM ve KT'nin birlikte kullanılmasıyla belirlenen ürün karması sonucunun, geleneksel yönteme göre belirlenen ürün karması sonucundan daha kârlı olup olmadığını araştırmadan önce öncelikle FDM'e göre kullanılan kapasiteler dikkate alınarak saf tamsayılı programlama ile model kurulmuş ve çözümlenerek ürün karması tespit edilmiştir. Daha sonra KT'e göre toplam kapasiteler dikkate alınarak saf tamsayılı programlama ile model kurulmuş ve çözümlenerek ürün karması tespit edilmiştir. Son olarak her iki yöntem birlikte kullanılarak saf tamsayılı programlama ile model kurulmuş ve çözümlenerek ürün karması tespit edilmiştir. Sonuç olarak aşağıda Tablo 13, Tablo 14 ve Tablo 15'te sirasıyla FDM'e göre, KT’e göre ve entegre modele göre gelir tabloları düzenlenmiş ve elde edilen kârlar hesaplanmıştır.

Tablo 13. FDM'e Göre Ürün Karmas1 Kârlılı̆̆1 (TL/1.000 birim)

\begin{tabular}{|c|c|}
\hline $\begin{array}{l}\text { Satışlar }(7,45 \times 0+11,11 \times 1.923+11,65 \times 1.385+12,50 \times 1.813+16,75 \times 2.286+25,55 \times 1 \\
129+9,60 \times 3.611+11,95 \times 1.463+7,69 \times 1.724+18,20 \times 333)\end{array}$ & $173.215,34$ \\
\hline $\begin{array}{l}\text { (-) Değişken Gid. }(5,12 \times 0+5,79 \times 1.923+5,89 \times 1.385+7,13 \times 1.813+14,45 \times 2.286+ \\
22,3 \times 129+6 \times 3.611+5 \times 1.463+6,15 \times 1.724+14 \times 333)\end{array}$ & $\begin{array}{l}(112.373,5) \\
1\end{array}$ \\
\hline Katk1 Pay1 & $60.841,83$ \\
\hline (-) Sabit Gid. $(150.000 \times 0,2809+43.200 \times 0,01 \times 15+43.200 \times 0,02 \times 16)$ & $(35.371,38)$ \\
\hline Kâr & $25.470,45$ \\
\hline
\end{tabular}

Tablo 14. KT’e Göre Ürün Karması Kârlılığı (TL/1.000 birim)

\begin{tabular}{|l|l|}
\hline Satı̧lar $(7,45 \times 374+11,11 \times 1.923+11,65 \times 1.385+12,50 \times 1.813+16,75 \times 2.285+$ & $178.324,83$ \\
$25,55 \times 0+9,60 \times 3.611+11,95 \times 1.463+7,69 \times 3.245+18,20 \times 0)$ & \\
\hline $\begin{array}{l}\text { (-) Ham. Mal. }(2,67 \times 374+3,02 \times 1.923+3,02 \times 1.385+3,72 \times 1.813+8,13 \times 2.285+ \\
12,78 \times 0+4,18 \times 3.611+1,34 \times 1.463+3,84 \times 3.245+8,64 \times 0)\end{array}$ & $(65.825,35)$ \\
\hline Süreç Katk1s1 (throughput) & $112.499,48$ \\
\hline $\begin{array}{l}\text { (-) Faal.Gid. } \\
150.000 \times 0,2809+43.200 \times 0,011 \times 15+43.200 \times 0,02 \times 16+900.000 \times 0,012+90.000 \times 0,129\end{array}$ & $(85.497)$ \\
\hline Kâr & $\mathbf{2 7 . 0 0 2 , 4 8}$ \\
\hline
\end{tabular}

Tablo 15. Entegre Modele Göre Ürün Karması Kârlılığı (TL/1.000 birim)

\begin{tabular}{|c|c|}
\hline $\begin{array}{l}\text { Satışlar }(7,45 \times 0+11,11 \times 1.923+11,65 \times 1.385+12,50 \times 1.813+16,75 \times 2.286+25,55 \times \\
145+9,60 \times 3.611+11,95 \times 1.463+7,69 \times 3.262+18,20 \times 0)\end{array}$ & 179.390,76 \\
\hline $\begin{array}{l}\text { (-) Ham.Mal. }(2,67 \times 0+3,02 \times 1.923+3,02 \times 1.385+3,72 \times 1.813+8,13 \times 2.286+12,78 \\
\text { x } 145+4,18 \times 3.611+1,34 \times 1.463+3,84 \times 3.262+8,64 \times 0)\end{array}$ & $(66.753,28)$ \\
\hline Süreç katkıs1 (throughput) & $112.637,48$ \\
\hline $\begin{array}{l}\text { (-) Faal.Gid. }(150.000 \times 0,2809+43.200 \times 0,011 \times 15+43.200 \times 0,02 \times 16+900.000 \times \\
0,012+90.000 \times 0,129)\end{array}$ & (85.497) \\
\hline Kâr & $27.140,48$ \\
\hline
\end{tabular}

Yapılan bu hesaplamalarda görüldüğü üzere, geleneksel tam maliyet sisteminde birim kârlar dikkate alınarak belirlenen ürün karması ile elde edilen kâr 22.203,86 TL, FDM'e göre kâr 25.470,45 TL, KT'e göre kâr 27.002,48 TL'dir. FDM ve KT'nin birlikte kullanılmasıyla elde edilen kâr ise 27.140,48 TL'dir. Görülmektedir ki FDM ve KT'nin birlikte kullanılması yoluyla elde edilen işletme kârı diğer yöntemlere göre daha yüksektir. 


\section{SONUÇ}

Bu çalışmanın amacı FDM ve KT'nin birlikte kullanılarak en uygun ürün karmasını belirleme ve sonucun işletme kârlılığına etkisini ortaya koymaktır. Bu çerçevede gıda ambalaj ürünleri sektöründe faaliyet gösteren bir imalat işletmesinde tanımlayıcı ve keşifsel olay çalışmaları gerçekleştirilmiştir. İşletmede yapılan araştırmada 10 tane ürün incelenmiştir. İncelenen 10 ürünün üretimi için gereken kapasite, mevcut kapasiteyi aşmaktadır dolayısıyla bu makinelerde (GN ve TFT makineleri) kısıt (darboğaz) söz konusudur. Yapılan analizler sonucunda FDM, KT ve her iki yöntemin birlikte kullanılması ile belirlenen ürün karmalarının, geleneksel tam maliyet sistemine göre belirlenen ürün karmasından daha kârlı sonuç yarattığı sonucu tespit edilmiştir. Ayrıca FDM ve KT'nin birlikte kullanılmasıyla, ayrı ayrı FDM ve KT'e göre daha yüksek kâr elde edildiği tespit edilmiştir. Bu sonuç gıda ambalaj ürünleri sektöründe faaliyet gösteren bir imalat işletmesinde tespit edilmiş olup, aynı sektörde faaliyet gösteren benzer koşullara sahip işletmeler için de bu sonuca varılabilir. Sonuç olarak gida ambalaj sektöründe faaliyet gösteren ve benzer koşullara sahip işletmelerde en uygun ürün karması kararlarında FDM ve KT'nin birlikte kullanılması ile yüksek kârlar sağlanabilir sonucuna varılabilmektedir.

\section{KAYNAKLAR}

Alsmad1- Majed, Ahmad-Almanı, Zulfiqar- Khan, (2014), "Implementing An Integrated ABC And TOC Approach To Enhance Decision Making in a Lean Context-A Case Study”, International Journal Of Quality \& Reliability Management, 31(8), pp.906-920.

Blackstone- John H., Jr., (2001), “Theory Of Constraints - A Status Report”, International Journal Of Production Research, 39(6), pp. 1053-1080.

Fu- Anabella, (2000), “Theory of Constraints and Activity-Based Costing”, Business Review, 2(2), pp. 66-74.

Goldratt- Eliyahu M. \& Robert E.- Fox, (1986), The Race, First Edition, North River Press, Inc., USA.

Hillier- F. S. \& G. J.- Lieberman, (1995), Introduction to Mathematical Programming, McGraw-Hill Publishing Company.

Huang- Shaio Yan, Hsueh Ju- Chen, An An- Chıu, Chih Pin- CHEN, (2014), "The Application Of The Theory Of Constraints And Activity-Based Costing To Business Excellence: The Case Of Automotive Electronics Manufacture Firms”, Total Quality Management, 25(5), pp. 532-545.

Izma1lov- Azar, (2014), "If Your Company Is Considering The Theory Of Constraints”, 10th International Strategic Management Conference Procedia - Social and Behavioral Sciences, 150, pp. 925-929.

Kee- Robert \& Charles- Schmıdt, (2000), “A Comparative Analysis of Utilizing Activity-Based Costing and The Theory of Constraints ForMaking Product-Mix Decisions”, International Journal of Production Economics, 63, pp. 1-17. 
Kee- Robert, (1995), "Integrating Activity-Based Costing With The Theory of Constraints To Enhance Production Related Decision Making”, Accounting Horizons, 9(4), pp. 48-61.

Küçüksavaş- Nihat, (1992), Kısmi Maliyet Sistemleri ve Katkı Payı Analizi, Birinci Bask1, Adana.

Louderback- Joseph G. \& J. Wayne- Patterson, (1996), “Theory of Constraints Versus Traditional Management Accounting”, Accounting Education, 1(2), pp. 189.

Macarthur- John B., (1993), "Theory of Constraints and Activity-Based Costing: Friends or Foes?”, Cost Management, Summer, pp. 50-56.

Macpherson- Ian, Ross- Unitoker \& Paul Ainsworth, (2000), "Case Study in the Contemporary World of Research: Using Notions of Purpose, Place, Process and Product to Develop Some Principles for Practice”, International Journal of Research Methodology, 3(1), pp. 49-61.

Massood- Yahya Zadeh, (1998), "Product-Mix Decisions Under Activity-Based Costing With Resource Constraints and Non-proportional Activity Costs”, The Journal of Applied Business Research, 14(4), pp. 39-45.

Perkıns- David, Jonathan- Stewart \& Scott- Stovall, (2002), "Using Excel, TOC, and ABC to Solve Product Mix Decisions With More Than One Constraint”, Management Accounting Quarterly, 3(3), Spring, pp. 1-10.

Render- Barry, Ralph- M. Stair, Jr., Michael- E. Hanna \& Trevor- S. Hale, (2018), Quantitative Analysis for Management, Global Edition, Pearson Education Limited.

Salafatınos- Chris, (1995), "Integrating The Theory of Constraints and Activity-Based Costing”, Journal of Cost Management, 9(3), pp. 58-67.

Tanış- Veyis Naci, (1999), "Faaliyete Dayalı Maliyet Yönteminin Anlamı, Önemi ve Faydaları", H.Ü. İktisadi ve İdari Bilimler Fakültesi Dergisi, 17(2), ss.147-158.

Tsa1, W.-H., Chang, J.-C., Hsieh, C.-L., Tsaur, T.-S., Wang, C.-W., (2016), "Sustainability Concept in Decision-Making: Carbon Tax Consideration for Joint Product Mix Decision”, Sustainability (8), 1232, pp.1-22.

Tsa1- Wen Hsien, Hui Chiao- Chena, Jun Der- Leua, Yao Chung- Changa \& ThomasW. Lin, (2013), “A Product-Mix Decision Model Using Green Manufacturing Technologies Under Activity-Based Costing”, Journal of Cleaner Production, 57, pp. 178-187.

Ulucan- Aydın, (2004), Yöneylem Araştırması: Bilgisayar Destekli/Uygulamalı Modelleme, Hacettepe Üniversitesi İİF Yayınları No. 29.

Yın- Robert K., (1994), Case Study Research: Design and Methods, Second Edition, Sage Publications, USA. 
Zhuang-Z., Chang- S., (2017), "Deciding Product Mix Based On Time-Driven Activity-Based Costing By Mixed Integer Programming”, Journal of Intelligent Manufacturing (28), pp.959-974.

EKLER

Tablo E1. Model İçin Gerekli Verilerin Tespit Edilmesi

\begin{tabular}{|l|l|l|l|l|l|l|l|l|l|l|}
\hline & $\mathbf{X 1 1}$ & $\mathbf{X 2 1}$ & $\mathbf{X 3 1}$ & $\mathbf{X 4 1}$ & $\mathbf{X 5 1}$ & $\mathbf{X 6 1}$ & $\mathbf{X 7 1}$ & $\mathbf{X 8 1}$ & $\mathbf{X 9 1}$ & $\mathbf{X 1 0 1}$ \\
\hline $\mathrm{P}_{\mathrm{i}}(\mathrm{TL} / 1.000$ birim) & 7,45 & 11,11 & 11,65 & 12,50 & 16,75 & 25,55 & 9,60 & 11,95 & 7,69 & 18,20 \\
\hline $\mathrm{c}_{\mathrm{i} 0}(\mathrm{TL} / 1.000$ birim) & 2,67 & 3,02 & 3,02 & 3,72 & 8,13 & 12,78 & 4,18 & 1,34 & 3,84 & 8,64 \\
\hline $\mathrm{D}_{\mathrm{i}}(1.000$ birim) & 2.174 & 1.923 & 1.385 & 1.813 & 2.286 & 1.091 & 3.611 & 1.463 & 5.000 & 333 \\
\hline cyc $_{\mathrm{i}}($ çevrim/dk) & 15 & 15 & 15 & 15 & 13 & 13 & 25 & 15 & 16 & 9 \\
\hline $\mathrm{q}_{\mathrm{i} 11}$ & 1,15 & 1,30 & 1,30 & 1,60 & 3,50 & 5,50 & 1,80 & 4,10 & 2 & 4,50 \\
\hline $\mathrm{q}_{\mathrm{i} 21}$ & 66,66 & 66,66 & 66,66 & 66,66 & 100 & 166,66 & 0 & 0 & 0 & 0 \\
\hline $\mathrm{q}_{\mathrm{i} 31}$ & 0 & 0 & 0 & 0 & 0 & 0 & 125 & 83,33 & 83,33 & 200 \\
\hline $\mathrm{q}_{\mathrm{i} 41}$ & 100 & 100 & 100 & 100 & 100 & 100 & 0 & 0 & 0 & 0 \\
\hline $\mathrm{q}_{\mathrm{i} 51}$ & 0 & 0 & 0 & 0 & 0 & 0 & 10 & 10 & 10 & 10 \\
\hline $\mathrm{q}_{\mathrm{i} 22}$ & 1 & 1 & 1 & 1 & 1 & 1 & 0 & 0 & 0 & 0 \\
\hline $\mathrm{q}_{\mathrm{i} 32}$ & 0 & 0 & 0 & 0 & 0 & 0 & 1 & 1 & 1 & 1 \\
\hline $\begin{array}{l}\text { Aylik maksimum üretim } \\
(1.000 \text { birim) }\end{array}$ & 9.720 & 9.720 & 9.720 & 9.720 & 5.616 & $3.369,6$ & 8.640 & 7.760 & $8.294,4$ & 1.944 \\
\hline
\end{tabular}

Tablo E2. Model İçin Gerekli Verilerin Hesaplanması

\begin{tabular}{|c|c|c|c|c|c|c|c|c|c|c|}
\hline & X11 & $\mathrm{X} 21$ & X31 & X41 & X51 & X61 & X71 & X81 & X91 & X101 \\
\hline $\begin{array}{l}\mathrm{P}_{\mathrm{i}-} \mathrm{C}_{\mathrm{i} 0} \quad \mathrm{X}_{\mathrm{i} 1} \\
(\mathrm{TL} / 1.000 \\
\text { birim }\end{array}$ & 4,78 & 8,09 & 8,63 & 8,78 & 8,62 & 12,77 & 5,42 & 10,61 & 3,85 & 9,56 \\
\hline $\begin{array}{ll}\mathrm{C}_{11} & \mathrm{q}_{\mathrm{i} 11} \\
\mathrm{X}_{\mathrm{i} 1} & \end{array}$ & $\begin{array}{l}0,32304 \\
=0,2809 \\
\mathrm{x} 1,15\end{array}$ & $\begin{array}{l}0,36517 \\
=0,2809 \\
\mathrm{x} 1,3\end{array}$ & $\begin{array}{l}0,36517 \\
=0,2809 \\
\mathrm{x} 1,3\end{array}$ & $\begin{array}{l}0,44944 \\
=0,2809 \\
\mathrm{x} 1,6\end{array}$ & $\begin{array}{l}0,98315 \\
=0,2809 \\
x 3,5\end{array}$ & $\begin{array}{l}1,54495 \\
=0,2809 \\
\times 5,5\end{array}$ & $\begin{array}{l}0,50562 \\
=0,2809 \\
\mathrm{x} 1,8\end{array}$ & $\begin{array}{l}1,15169 \\
=0,2809 \\
\times 4,1\end{array}$ & $\begin{array}{l}0,5618= \\
0,2809 \\
\text { x } 2\end{array}$ & $\begin{array}{l}1,26405 \\
=0,2809 \\
\mathrm{x} 4,5\end{array}$ \\
\hline $\mathrm{q}_{\mathrm{i} 21}$ & $\begin{array}{l}0,7333= \\
0,011 x \\
66,66\end{array}$ & $\begin{array}{l}0,7333= \\
0,011 x \\
66,66\end{array}$ & \begin{tabular}{|l|}
$0,7333=$ \\
$0,011 \mathrm{x}$ \\
66,66
\end{tabular} & $\begin{array}{l}0,7333= \\
0,011 x \\
66,66\end{array}$ & $\begin{array}{l}1,1= \\
0,011 \mathrm{x} \\
100\end{array}$ & $\begin{array}{l}1,8333= \\
0,011 x \\
166,66\end{array}$ & 0 & 0 & 0 & 0 \\
\hline $\mathrm{q}_{\mathrm{i} 31}$ & 0 & 0 & 0 & 0 & 0 & 0 & $\begin{array}{l}2,5= \\
0,02 x \\
125\end{array}$ & $\begin{array}{l}1,6666= \\
0,02 x \\
83,33\end{array}$ & $\begin{array}{l}1,6666= \\
0,02 x \\
83,33\end{array}$ & $\begin{array}{l}4=0,02 x \\
200\end{array}$ \\
\hline $\mathrm{q}_{\mathrm{i} 41}$ & \begin{tabular}{|l|}
$1,2=$ \\
$0,012 \mathrm{x}$ \\
100
\end{tabular} & \begin{tabular}{|l|}
$1,2=$ \\
$0,012 \mathrm{x}$ \\
100
\end{tabular} & $\begin{array}{l}1,2=0,0 \\
12 \times 100\end{array}$ & $\begin{array}{l}1,2=0,0 \\
12 \times 100\end{array}$ & $\begin{array}{l}1,2=0,0 \\
12 \times 100\end{array}$ & $\begin{array}{l}1,2=0,0 \\
12 \times 100\end{array}$ & 0 & 0 & 0 & 0 \\
\hline $\mathrm{q}_{\mathrm{i} 51}$ & 0 & 0 & 0 & 0 & 0 & 0 & $\begin{array}{l}1,29= \\
0,0129 x \\
10\end{array}$ & $\begin{array}{l}1,29= \\
0,0129 x \\
10\end{array}$ & $\begin{array}{l}1,29= \\
0,0129 x \\
10\end{array}$ & $\begin{array}{l}1,29= \\
0,0129 x \\
10\end{array}$ \\
\hline $\mathrm{q}_{\mathrm{i} 12}$ & 0 & 0 & 0 & 0 & 0 & 0 & 0 & 0 & 0 & 0 \\
\hline $\begin{array}{l}\mathrm{C}_{22} \\
\mathrm{X}_{\mathrm{i} 2}\end{array}$ & $\begin{array}{l}44,42= \\
44,42 \times 1\end{array}$ & $\begin{array}{l}44,42= \\
44,42 \times 1\end{array}$ & $\begin{array}{l}44,42= \\
44,42 \times 1\end{array}$ & $\begin{array}{l}44,42= \\
44,42 \times 1\end{array}$ & $\begin{array}{l}44,42= \\
44,42 \times 1\end{array}$ & $\begin{array}{l}44,42= \\
44,42 \times 1\end{array}$ & 0 & 0 & 0 & 0 \\
\hline $\begin{array}{ll}\mathrm{C}_{32} & \mathrm{q}_{\mathrm{i} 32} \\
\mathrm{X}_{\mathrm{i} 2} & \end{array}$ & 0 & 0 & 0 & 0 & 0 & 0 & $\begin{array}{l}14,807= \\
14,807 \\
x 1\end{array}$ & $\begin{array}{l}14,807= \\
14,807 \\
x 1\end{array}$ & $\begin{array}{l}14,807= \\
14,807 \\
x 1\end{array}$ & $\begin{array}{l}14,807= \\
14,807 \\
x 1\end{array}$ \\
\hline
\end{tabular}

